\title{
La perduración del poder en un espacio arquitectónico simbólico. La torre T-3 del asentamiento protohistórico de L’Assut (Tivenys, Baix Ebre, Tarragona)
}

\author{
La perduration du pouvoir dans un espace architectonique symbolique. La tour T-3 \\ du site protohistorique de L'Assut (Tivenys, Baix Ebre, Tarragone)
}

Jordi Diloli Fons (*)

\section{RESUMEN}

Los trabajos arqueológicos efectuados en el asentamiento protohistórico de L'Assut (Tivenys, Baix Ebre, Tarragona) han permitido localizar una torre fortificada de planta circular (T3), construida durante el siglo VI a.n.e. Este tipo de estructuras se ha relacionado en áreas vecinas con una intencionalidad elitista ejercida por un grupo de poder emergente mediante el simbolismo arquitectónico, desapareciendo el modelo a inicios del Ibérico Pleno. En el caso de la torre T3, por el contrario, el edificio se integra en el sistema defensivo de un poblado de nueva planta fundado a mediados del siglo $\mathrm{V}$ a.n.e., subsistiendo su representatividad al convertirse en la residencia del estamento dirigente del oppidum. A finales del siglo III a.n.e., la residencia fortificada es destruida intencionadamente, posiblemente como una demostración del poder de Roma sobre las élites indígenas, en un momento de convulsión provocado por la presencia romana en el nordeste de la Península Ibérica, mientras que el poblado continuará ocupado hasta finales del siglo II-inicios del I a.n.e.

\section{RÉSUMÉ}

Les fouilles effectués dans le site protohistorique de L'Assut (Tivenys, Tarragone) ont permis de localiser une tour fortifiée de plante circulaire (T3) construite durant le VIe siècle a.n.e. Ce type de structures s'est rattaché dans des aires voisines avec une intentionnalité élitiste

(*) Seminari de Protohistoria i arqueología. Universitat Rovira i Virgili. Avinguda Catalunya 35. 43002 Tarragona. Correo electrónico: jordi.diloli@urv.cat. La investigación actual en el yacimiento arqueológico de L'Assut, se incluye en el proyecto del MCINN "La arquitecture del poder en el Valle del Segre y en el Mediterráneo noroccidental entre el III y el I milenio a.n.e." HAR2008-05256.

Recibido: 24-III-2009; aceptado: 24-IV-2009. exercée par un groupe de pouvoir émergent à travers du symbolisme architectonique, en disparaissant le modèle aux commencements de le periode Ibérique Pleine. Dans le cas de la tour T3, au contraire, l'édifice est intégré dans le système défensif d'un lieu habité de nouvelle plante, fondé au milieu du Ve siècle a.n.e., en subsistant sa représentativité après s'être converti en résidence de la classe dirigeante de l'oppidum. À la fin du IIIe siècle a.n.e., la résidence fortifiée est détruite intentionnellement, possiblement comme une démonstration du pouvoir de Rome sur les élites indigènes, dans un moment de convulsion provoqué par la présence romaine dans le nord-est de la Péninsule Ibérique, alors que le lieu habité restera occupé jusqu'aux fins du IIe siècle a.n.e.

Palabras clave: Protohistoria; Casa-torre; Recinto fortificado; Iberos; Curso inferior del río Ebro.

Mots clé: Protohistoire; Maison à tour; Enceinte fortifié; Ibères; Cours inférieur de le fleuve Ebre.

\section{INTRODUCCIÓN}

El asentamiento de L'Assut fue descubierto en el año 1988, en el transcurso de unas prospecciones arqueológicas efectuadas en el curso inferior del Ebro por un equipo formado por miembros de la Universitat de Barcelona y del Servei d'Arqueologia de la Diputació de Castelló. Durante estos trabajos, que permitieron la localización de diversos yacimientos protohistóricos situados en ambos márgenes del río Ebro, se identificó el núcleo del Ligallo de L'Assut como un pequeño asentamiento ibérico, degradado por diversas acciones antrópicas y naturales, estableciéndose su cronología entre los siglos III-II a.n.e. (Mascort et al. 1990). 
En el año 2000, un equipo de investigación de la Universitat Rovira i Virgili, decidió incluir las intervenciones arqueológicas en este yacimiento en un proyecto de investigación sobre los modelos de ocupación y evolución del poblamiento durante la Protohistoria en el curso inferior del Ebro, estableciéndose una planificación que preveía excavar anualmente en el asentamiento.

Siguiendo estos parámetros, se han efectuado hasta la actualidad nueve campañas de intervención arqueológica especialmente destinadas a delimitar el área ocupada, definir el urbanismo del poblado, especialmente el relacionado con las estructuras defensivas y concretar la secuencia ocupacional del mismo, con unos resultados que han permitido precisar una continuidad en la secuencia habitacional de L'Assut desde el siglo VII a.n.e. hasta finales del siglo II-inicios del I a.n.e., tratándose de uno de los pocos establecimientos protohistóricos del área del bajo Ebro con una acomodación poblacional superior a los 550 años.

Una de sus excepcionalidades está representada por la presencia de un edificio turriforme (T3), situado en el extremo superior de la colina e integrado en las fortificaciones del poblado. Se trata de una torre fortificada cuya construcción, a partir de los datos actuales, podríamos fechar a partir de inicios del siglo VI a.n.e., con unas características similares a un arquetipo arquitectónico identificado en áreas vecinas como un modelo de hábitat característico del momento anterior al Ibérico Pleno, la "casa-torre" o "casa fortificada aislada" (Moret 2002, 2006; Moret et al. 2006), inexistente en épocas precedentes o posteriores, y que simboliza en el paisaje los profundos cambios socio-políticos que se producen en el bajo Ebro y regiones vecinas durante este período.

La arquitectura de estas "casas" las tipifica como residencias fortificadas aisladas, de planta circular y altura considerable, situadas en puntos estratégicos de fácil defensa y acceso a los principales recursos del territorio, interpretándose su función primordial a partir de la intencionalidad de los grupos dominantes que las erigen para mostrar una distinción sobre el conjunto social mediante la edificación de unas construcciones excepcionales que expresan este poder emergente a través de, entre otros factores, el simbolismo arquitectónico (Moret et al. 2006).

La torre descubierta en L'Assut cumple varios de estos parámetros, si bien al contrario de otros casos en que estas estructuras desaparecen a inicios del ibérico pleno, el edificio del Baix Ebre perdura, integrándose como uno de los principales componentes del sistema defensivo de un poblado de nueva planta que ocupará el mismo cerro a partir del siglo $\mathrm{V}$ a.n.e. En este caso, la imagen de autoridad subsistirá al convertirse la torre en la residencia de los gobernantes del oppi$d u m$, tal como lo sugiere el material recuperado en su interior en el transcurso de las excavaciones arqueológicas.

El edificio sufrirá un violento incendio a finales del siglo III-inicios del II a.n.e., sin que se constate ningún intento de recuperación de su contenido, a pesar de su importancia. Este hecho y la ausencia de elementos que revelen ningún tipo de violencia en el resto del asentamiento, que continuará ocupado hasta finales del siglo II-inicios del I a.n.e., parecen indicar que la destrucción de la torre se podría haber producido como un acto de represión ejemplar ejercido por un elemento externo, sobre las elites indígenas locales, en este caso una muestra de fuerza profesada posiblemente por los romanos para afirmar su autoridad en un momento de convulsión datado en ésta zona geográfica entre finales del siglo III a.n.e. e inicios del II a.n.e.

\section{SITUACIÓN Y ENTORNO DEL YACIMIENTO}

El yacimiento de L'Assut se encuentra ubicado en el municipio de Tivenys (Baix Ebre, Tarragona) en el margen izquierdo del río Ebro, ocupando el extremo superior y la vertiente sur/suroeste de un cerro que forma parte de las estribaciones montañosas que delimitan la terraza fluvial del Ebro.

La superficie ocupada por los restos arqueológicos procedentes de las sucesivas fases ocupacionales está fijada por la propia orografía del altiplano, delimitado por dos barrancos que descienden desde las elevaciones superiores desaguando en el Ebro, a los pies del promontorio. La accesibilidad al yacimiento se ve así condicionada por la topografía, siendo únicamente en la parte baja del altozano, cercana a la orilla fluvial y en el extremo superior de la colina donde se pueden habilitar los posibles pasos o puertas que permitan acceder al interior del poblado. En el caso 
de la cima, tanto por su posición elevada como para proteger el acceso al núcleo, se sitúan las construcciones defensivas que separan el espacio urbanizado del exterior, modelándose a partir del siglo $\mathrm{V}$ a.n.e. una área habitada de aproximadamente $3.500 \mathrm{~m}^{2}$.

El cerro está formado por un conjunto geológico de origen jurásico constituido por dolomías, con presencia de rocas calcáreas y de los conglomerados cuaternarios típicos de las terrazas del río Ebro, disponiéndose a sus pies una cuenca rica en depósitos aluviales, esenciales en los procesos de explotación agropecuaria de esta región. Las formaciones geológicas que constituyen el paisaje proporcionarán también las materias primas con las que se abastecerán las estructuras del poblado protohistórico: la piedra calcárea y la arcilla. A nivel hidrológico, obviando el río Ebro, la zona es rica en vetas subterráneas y en fuentes, tal y como se desprende de los topónimos conservados en la región, caso del Barranc de les Fonts o de Les Fonts del Carme, relacionadas sobre todo con los tramos del Lias Inferior y del Jurásico, en los que se localizan importantes surgimientos de agua, sin olvidar los depósitos cuaternarios conglomeráticos, que, por su proximidad al Ebro conforman un gran nivel hidrogeológico.

Por otra parte, tal como hemos avanzado, la ubicación del yacimiento es excelente en cuanto a una posible explotación del territorio circundante, pues a los pies del altozano de L'Assut se extiende una amplia llanura de más de 400 ha, constituida esencialmente por suelos aluviales planos y profundos, con fácil acceso al agua, que pueden ser cultivados con técnicas muy rudimentarias. Asimismo, los llanos ligeramente más elevados que ascienden hacia las sierras presentan un tipo de paisaje igualmente aceptable para desarrollar labores agrícolas, especialmente cultivos de secano, que son los que ocupan hoy en día este espacio. Por otra parte, el acceso a determinadas materias primas de tipo mineralógico tampoco debió ser difícil para los habitantes de este núcleo, pues en sus proximidades se hallan diversos yacimientos minerales en forma de hard-grounds que pueden relacionarse con la explotación de materiales ferruginosos (Diloli 2002).

Es importante destacar también que la posición estratégica del asentamiento le proporcionaría un control visual absoluto sobre el río Ebro, inmejorable vía de comunicación entre la costa y el interior, siendo el camino por el cual llegarían los productos mediterráneos durante todo el período de ocupación del poblado, que como ya hemos indicado abarca desde el siglo VII a finales del II-inicios del I a.n.e. Asimismo, no se debe desestimar el acceso a las sierras a través del Ligallo de L'Assut, camino ganadero que se dirige a la cima de la sierra de Cardó donde, después de enlazar con el Ligallo de Quarts, cruza el Coll del Murtero -762 m- para descender por el sendero de Punta d'Àliga y por el Ligallo de la Caparreta hasta el llano del Burgar, y desde allí al mar.

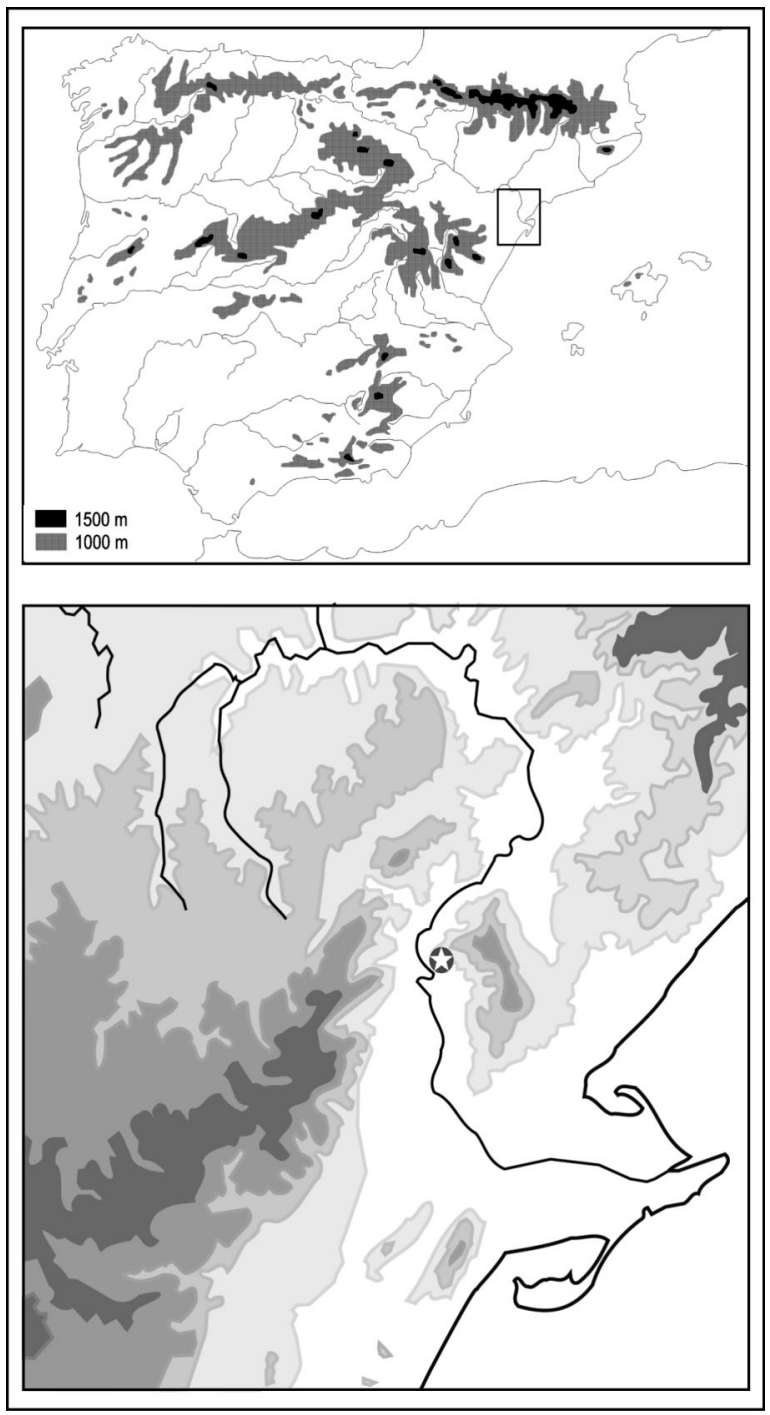

Fig. 1. Situación del poblado protohistórico de L'Assut (Tivenys, Baix Ebre, Tarragona). 


\section{CONTEXTO \\ HISTÓRICO-ARQUEOLÓGICO DE LA ZONA}

El curso inferior del Ebro presenta una abundante evidencia poblacional a partir de la Primera Edad del Hierro, perdurando, a pesar de los cambios en el patrón ocupacional, hasta su sustitución por los modelos territoriales impulsados por Roma.

De hecho, la evolución del poblamiento en esta área geográfica ha estado claramente determinada por la presencia del río Ebro y de sus afluentes, si-

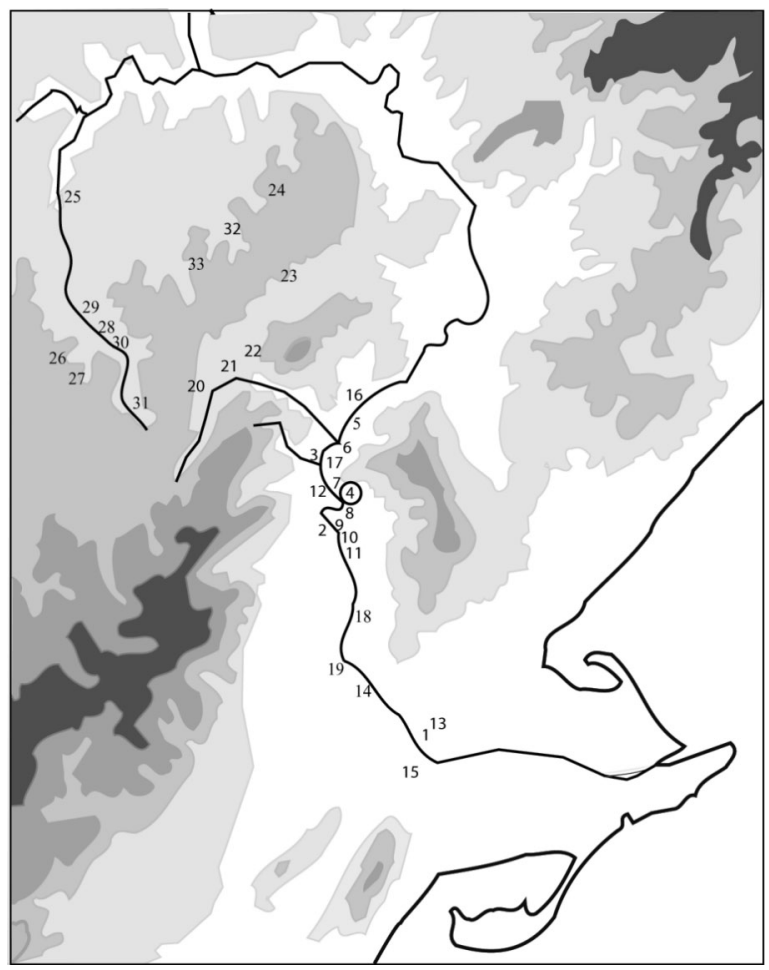

Fig. 2. Principales yacimientos arqueológicos del Baix Ebre y la Terra Alta durante la Primera Edad del Hierro. 1.- Tossal Redó; 2.- Els Tossals; 3.- Turó de Xalamera; 4.- L'Assut; 5.- El Martorell; 6.- Aldovesta; 7.- Barranc Fondo; 8.- Mas d'en Serra; 9.- Casa de l'Assistent; 10.- Plana de la Mora 1; 11.- Plana de la Mora 2; 12.- Barranc de les Fonts; 13.- Mas de Mussols (nec.); 14.- Mianes (nec.); 15.- L'Oriola (nec.); 16.- Lo Toll; 17.- Castellot de la Roca Roja; 18.- Castell de Sant Joan; 19.- Pla de les Sitges; 20.- Font de Leure; 21.- Els Vilassos 2; 22.- Tossal del Moro de Bot; 23.- Coll del Moro (nec.); 24.- Turó del Calvari; 25.- Tossal del Moro; 26.- Tossal Redó; 27.- Piuró del Barranc Fondo; 28.- La Gessera; 29.- Castell d'Almudéfar; 30.- El Puig; 31.- La Serra Mitjana; 32.- Coll del Moro del Xollat; 33.- Varavalls (nec.). nec. $=$ necrópolis. tuándose en sus márgenes la mayoría de lugares de hábitat, con el propósito de controlar los recursos y los accesos de esta gran región, generándose un modelo de ocupación que persigue un dominio territorial a partir del establecimiento de una serie de asentamientos en cerros estratégicos dispuestos a ambos lados del río, con interrelación visual entre ellos, respondiendo a características comunes en que primarán las condiciones estratégicas de defensa, visibilidad y control sobre los territorios y recursos colindantes.

Este patrón ocupacional evolucionará asociado a los profundos cambios que afectarán a la población de esta región a partir del siglo VI a.n.e., documentándose una intensa transformación de tipo socio-político que sufrirá diversos reajustes hasta la eclosión, a mediados del siglo $\mathrm{V}$ a.n.e., de lo que denominamos Ibérico Pleno, momento en que se establecerá una organización territorial en base a la jerarquización y especialización de los centros de hábitat (Diloli 2002). Este modelo perdurará hasta finales del siglo II a.n.e., o incluso en algunos casos principios del siglo I a.n.e., cuando el nuevo orden impulsado desde Roma se orientará hacia una nueva estrategia territorial, basada en unos parámetros políticos y económicos diferentes a los ibéricos.

\section{L'ASSUT. LECTURA ARQUITECTÓNICA}

El poblado de L'Assut ejemplifica en el curso inferior del Ebro la ocupación continuada de un mismo paisaje protohistórico. Después de las intervenciones arqueológicas efectuadas entre los años 2000 y 2008 , podemos estructurar su ocupación en cuatro fases bien diferenciadas.

Si bien en un trabajo anterior establecíamos esta partición en tres fases, Assut 1 (siglo VI a 450 a.n.e.), Assut 2 (450-175/150 a.n.e.) y Assut 3 (175/150-100 a.n.e.) (Diloli y Bea 2005), planteábamos la posibilidad de que existiera una ocupación anterior, que se podría datar dentro de la Primera Edad del Hierro, sobre todo a partir de la presencia de algunos fragmentos de ánfora fenicia, todos ellos informes, pertenecientes a producciones procedentes del Círculo del Estrecho, enmarcables dentro de la forma Vuillemot R-1 o T-10.1.2.1 (Ramon 1995). Con los datos actuales, hemos podido confirmar la existencia de un volumen considerable de estos materiales y su asociación con algunas estructuras construidas directa- 


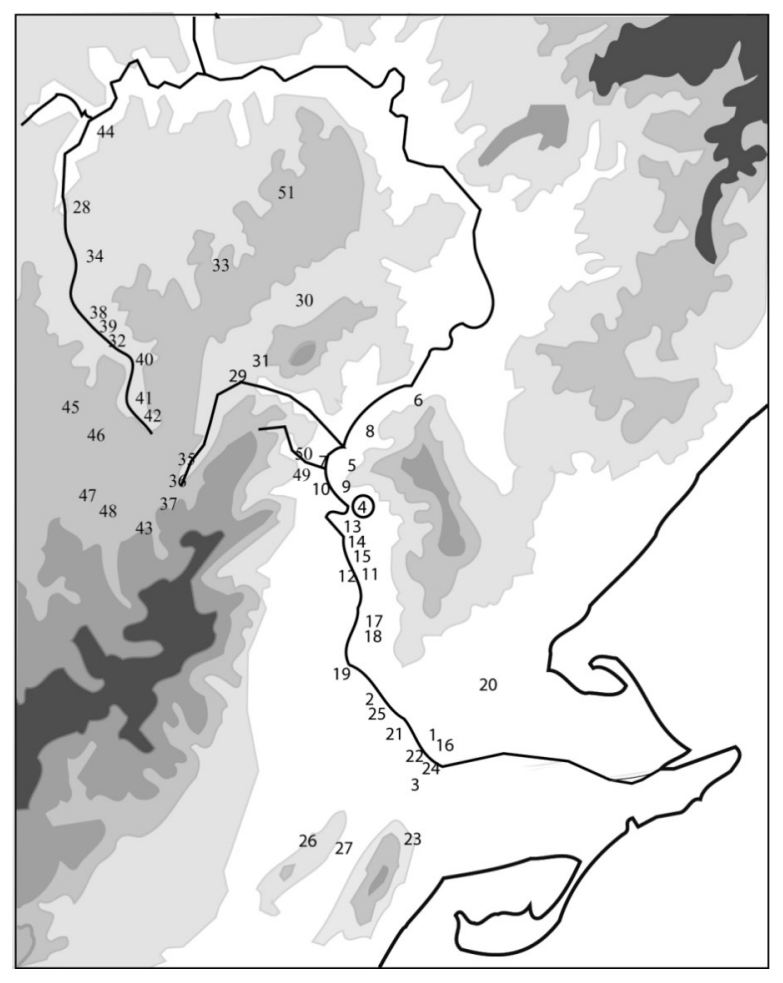

Fig. 3. Principales yacimientos arqueológicos del Baix Ebre y la Terra Alta durante época ibérica. 1.- Mas de Mussols (as. y nec.); 2.- Mianes (nec.); 3.- L'Oriola (nec.); 4.- L'Assut; 5.- Castellot de la Roca Roja; 6.- Turó de 1'Audí; 7.- Mas de Xalamera; 8.- El Martorell; 9.- La Torreta / Coll de Som; 10.- Les Trampes; 11.- Les Planetes; 12.- Les Valletes; 13.- Km. 14; 14.- Les Planes; 15.- Punta de Plana de la Mora; 16.- Barranc de Sant Antoni; 17.- Castell de Sant Joan; 18.- Hospital Verge de la Cinta; 19.- Pla de les Sitges; 20.- El Bordissal; 21.- La Carrova (nec.); 22.- Pla d'Empúries; 23.- Les Faixes Tancades de l'Antich; 24.- El Castell d'Amposta; 25.- Mianes; 26.- Castell dels Moros; 27.- Les Esquarterades; 28.- Tossal del Moro de Pinyeres; 29.- Els Vilassos I; 30.- Coll del Moro; 31.- Tossal del Moro de Bot; 32.- La Gessera; 33.- Coll del Moro del Borrasquer; 34.- El Castell; 35.- Els Vilans; 36.- Penya Gall; 37.- El Mollet; 38.- Castell d'Almudéfar; 39.- Els Carrascals; 40.- El Puig; 41.- Els Corralets; 42.- La Serra Mitjana; 43.- La Picossa; 44.- Camí dels Anoguerets; 45.- Sant Antoni de Calaceit; 46.- Les Ombries; 47.- Els Castellans; 48.- Mas de les Madalenes; 49.- Mas d'en Cid; 50.- Molaterra; 51.- Els Dolors. as. = asentamiento; nec. $=$ necrópolis.

mente sobre los conglomerados cuaternarios que forman la base geológica del cerro, sin ninguna relación con los muros posteriores. De esta manera, los avances en el conocimiento del conjunto ocupacional nos han permitido perfilar mejor aquella periodización, añadiendo una nueva fase, Assut 0, que acontecería entre mediados del si-

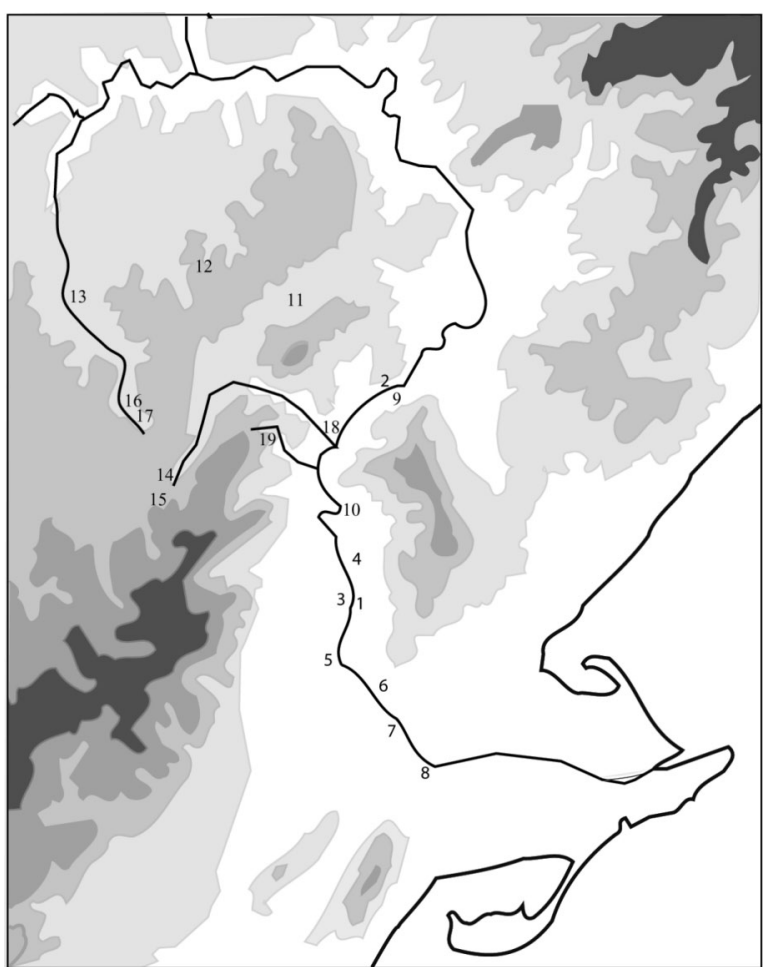

Fig. 4. Principales yacimientos arqueológicos del Baix Ebre y la Terra Alta durante época romana. 1.- Dertosa; 2.- Les Llomes; 3.- Horta Baixa; 4.- Barrugat; 5.- Pla de les Sitges; 6.- Masia Despatx; 7.- La Carrova; 8.- El Castell d'Amposta; 9.- Mas del Catxorro; 10.- Mas de Degà; 11.- Coll del Moro; 12.- Coll del Moro del Borrasquer; 13.- Castell d'Almudéfar; 14.- Penya Gall; 15.- El Mollet; 16.- Els Corralets; 17.- Serra Mitjana; 18.- Ligallo de Líxem; 19.- Pla de Fernando.

glo VII a.n.e. e inicios del siglo VI a.n.e., marcando el inicio de uso de este espacio como lugar de hábitat estable.

La segunda fase, Assut 1, estaría definida por la construcción de T3, posiblemente como ya hemos indicado a partir de inicios del siglo VI a.n.e., produciéndose a mediados del siglo $\mathrm{V}$ a.n.e. una planificación urbanística (fase Assut 2) dirigida a ocupar todo el cerro, que se basaría en la edificación de un gran complejo defensivo en el punto más elevado de la colina de L'Assut, a partir de la torre circular erigida durante la fase anterior, incorporándose ésta a la nueva estructura arquitectónica. La nueva construcción se basaría en la superposición de una serie de muros concéntricos formando una primera plataforma fortificada (P1) que englobaría la torre T3, reforzando su perímetro. Sobre esta plataforma, respetando T3, se construyen el resto de elementos de protección: 
un segundo bloque de muros concéntricos, apoyado en la plataforma $\mathrm{P} 1$, dejando entre ellos un espacio de circulación que recorre longitudinalmente el sistema defensivo, con una puerta en el lado noroccidental que permite el acceso desde el poblado al complejo defensivo a partir de unas escaleras, y posiblemente una zona de comunicación que enlazaría este pasillo con la torre T3, al estilo de un paso de ronda o camino protegido que comunicaría toda la fortificación.

El espacio habitacional se ordenaría a partir del sistema defensivo, extendiéndose por la cima y la vertiente sur/suroeste del cerro. Hasta ahora se ha localizado una calle que delimita un barrio de viviendas dispuesto en el extremo norte (BN), asociado al sistema defensivo, situado justo sobre el Ligallo de 1'Assut. Las casas de este barrio determinan, mediante su pared posterior, el límite norte del recinto poblacional, con refuerzos ocasionales que funcionan como contrafuertes o dando más consistencia al sistema de cierre.

Las recientes intervenciones en el yacimiento han permitido distinguir otra fase a finales del siglo III a.n.e., Assut 3, en la que se producen toda una serie de modificaciones arquitectónicas tanto en el sistema defensivo como en la zona de hábitat. En el caso de las defensas, se producirá una destrucción repentina de la torre T3 mediante un incendio que provocará el hundimiento de la estructura, sin que se recupere este espacio. Posiblemente asociado a este acontecimiento se rellenará el pasillo interior de la muralla, impidiendo la circulación por el mismo, quedando únicamente un ámbito abierto en el extremo norte del sistema defensivo, donde estaba la puerta que permitía el acceso desde el poblado y que ahora se tapia desde fuera con un nuevo tramo de muro. En el barrio norte la modificación del espacio urbanizado suprime la calle de la época anterior, que se ve ocupada por viviendas que superarán el tamaño de las casas de la fase 2 .

A partir de finales del siglo II o a principios del siglo I a.n.e. parece que el asentamiento se abandona pacíficamente, como denota la escasez de material arqueológico recuperado. Cuando menos, el final de la ocupación es confuso, pues no hay materiales cerámicos que daten este abandono de manera precisa, si bien se han localizado en niveles superficiales fragmentos de ánfora itálica entre los cuales cabe destacar un borde de Dressel 1B, datada en el siglo I a.n.e. Este proceso de abandono debe responder a los nuevos planteamientos organizativos relacionados con la ocupación romana de este territorio, que obligará de grado o por fuerza a la población ibérica a renunciar a su modo de vida para adaptarse a una nueva situación política, económica y social.

\section{LA TORRE T3}

El espacio que hemos denominado torre T3 se sitúa, como hemos señalado anteriormente, en el punto más alto del cerro de L'Assut, planificándose en el momento de su edificación según los datos actuales, como un edificio presuntamente aislado, de planta aproximadamente circular, con un diámetro exterior que oscila entre los 9 y los 9,20 m y una superficie útil interior de aproximadamente $18 \mathrm{~m}^{2}$.

A nivel constructivo, la estructura arquitectónica se erige a partir de un único muro formado por piedras de tamaño grande-medio unidas con barro, constituyendo un elemento macizo desde la base, que compone un único muro perimetral de entre 2 y 2,20 m de ancho. En la edificación se utiliza un aparejo formado por piedras ligeramente desbastadas, hecho que permite un mejor encaje entre ellas, conformando así un aparato muy sólido, situándose en el exterior las piedras más grandes, que en ningún caso superan los $80 \mathrm{~cm}$ de longitud. La anchura del muro perimetral, entre otros datos, indica la existencia de al menos un piso por encima del nivel de uso inferior. En este sentido cabe mencionar que en el punto donde la torre está mejor conservada su altura llega hasta los $3,50 \mathrm{~m}$.

El interior de la torre presenta, estratigráficamente, tres niveles principales, las UE 1304, 1306 y 1308. La primera, UE 1304, estaría formada por el derrumbe de la estructura, con presencia de muy pocos restos del incendio que destruyó el edificio, siendo de formación posterior a la cremación y sedimentada in situ. Situada por debajo de la anterior se encuentra la UE 1306, generada por la deflagración y cubriendo a 1308, del mismo momento cronológico. Estos dos niveles tienen numerosos residuos asociados a la devastación de la torre, habiéndose formado en el momento de la destrucción de la misma. La UE 1308 se sitúa directamente sobre el último pavimento de uso (UE 1311), cubriendo parte de la piedra que sirve de base a un pilar central. A título interpretativo, el nivel 1308 podría provenir 


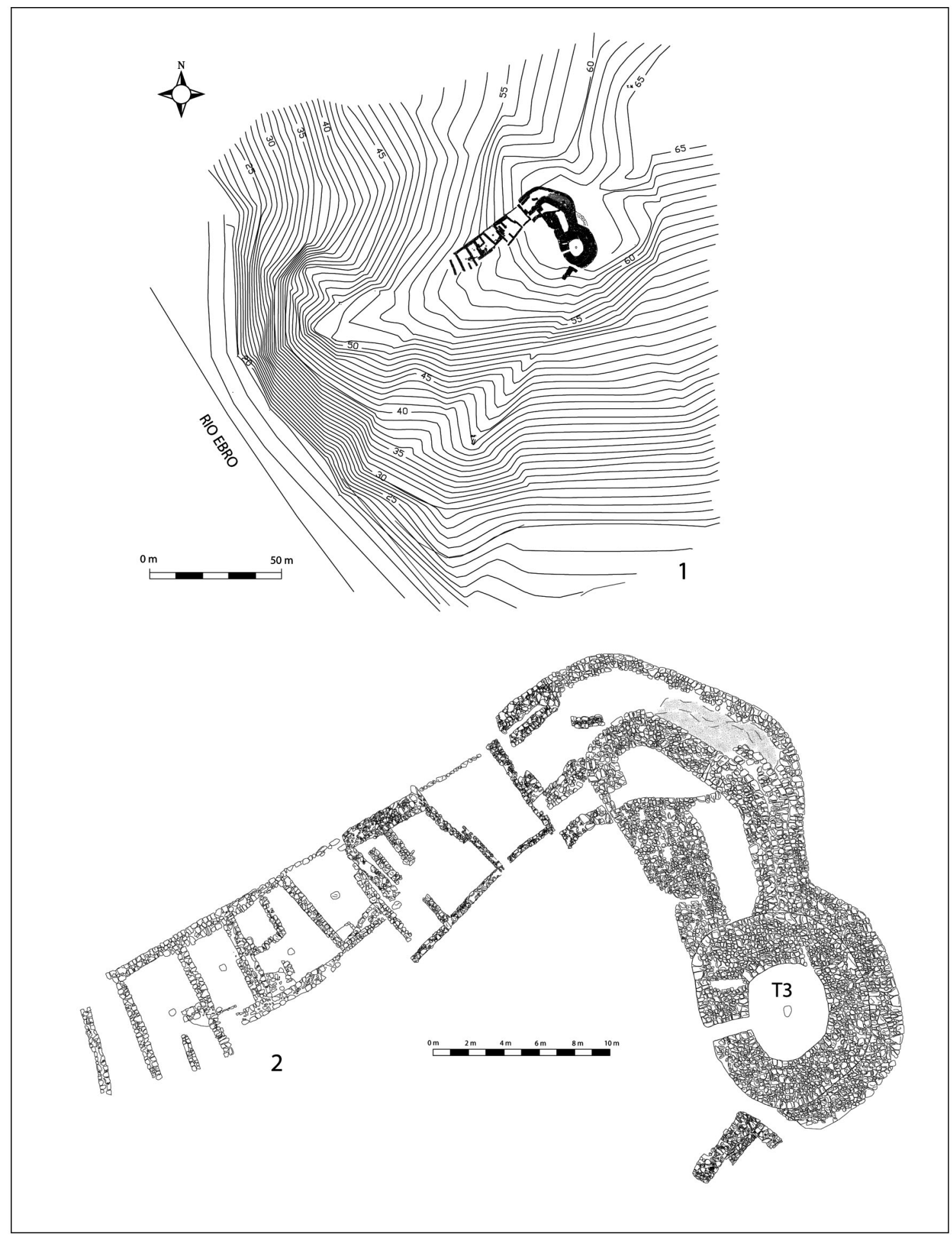

Fig. 5. 1.- Topografía de la colina donde se sitúa el asentamiento de L'Assut. 2.- Planta del asentamiento de L'Assut.

del derrumbe del techo del piso superior de la torre, tanto por los restos constructivos que se han localizado como por su disposición en el contexto estratigráfico. Debajo del pavimento 1311, fabricado con una arcilla muy fina apisonada, que tal como hemos indicado fue posiblemente el último

T. P., 66, N. ${ }^{\circ}$ 2, julio-diciembre 2009, pp. 119-142, ISSN: 0082-5638 doi: $10.3989 /$ tp.2009.09023 


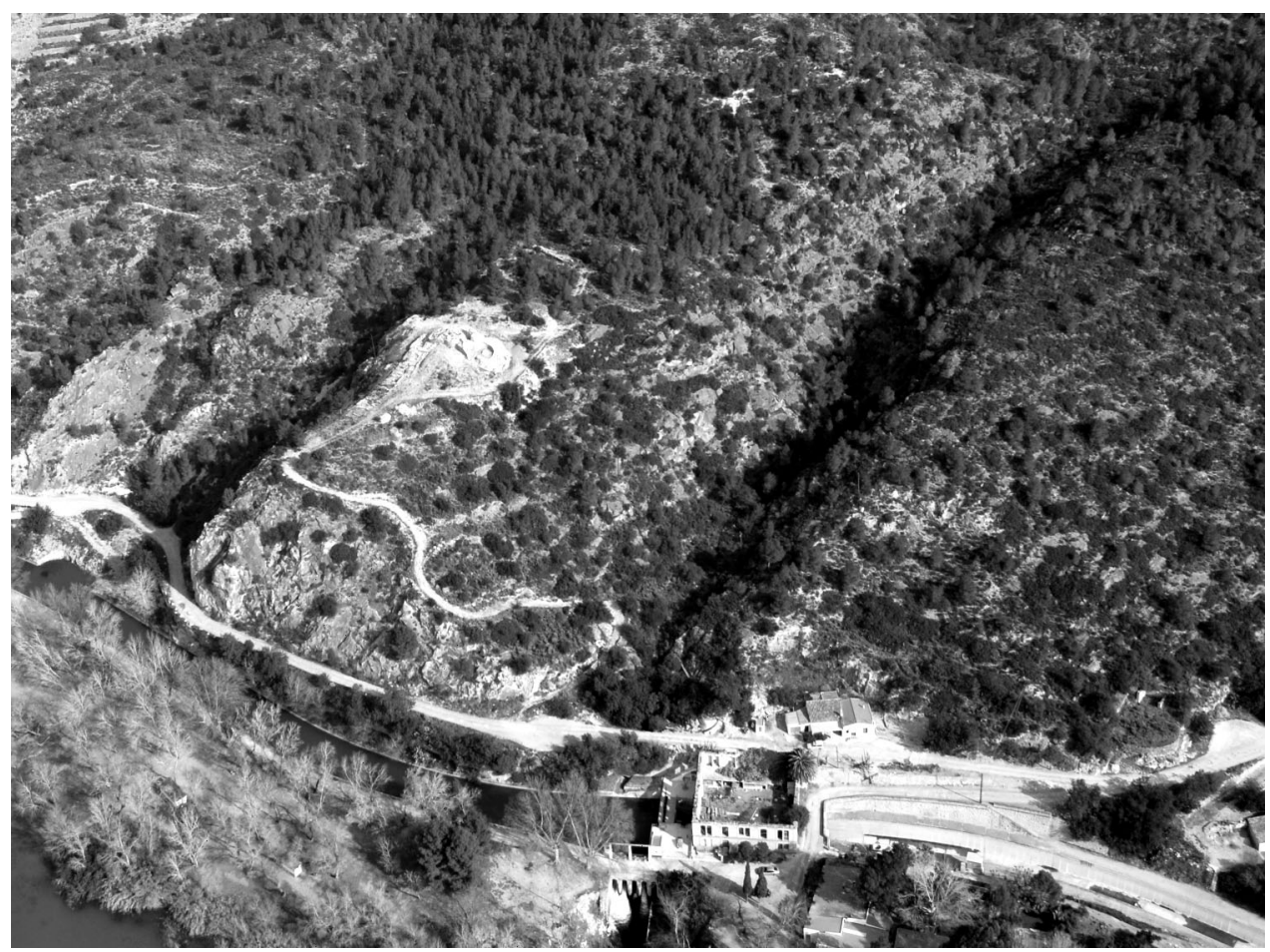

Lám. I. Vista general de L’Assut (Tivenys, Tarragona) y su entorno.

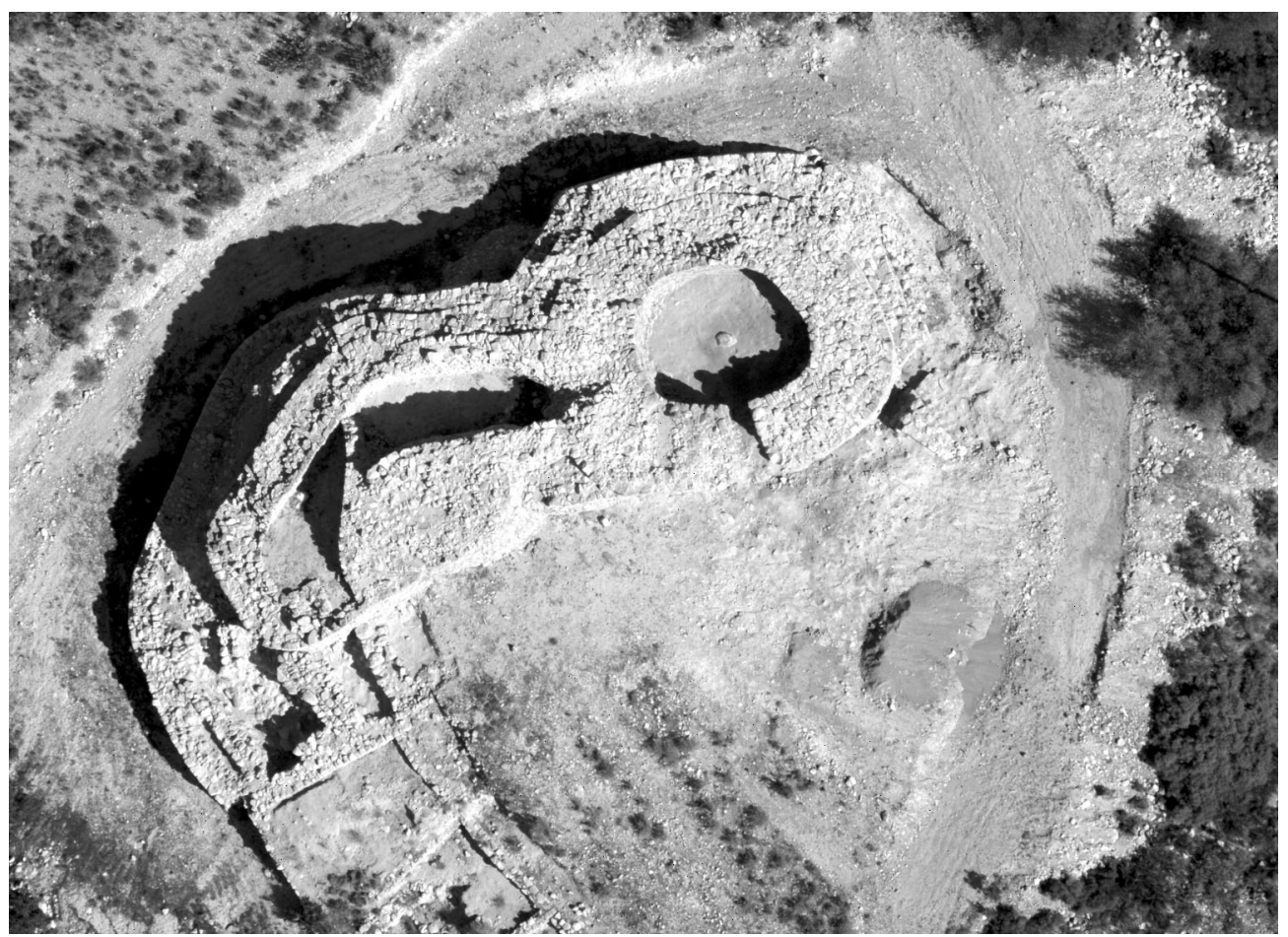

Lám. II. Sistema defensivo del asentamiento de l'Assut (Tivenys, Tarragona), con detalle de la torre T3.

T. P., 66, N. ${ }^{\circ}$ 2, julio-diciembre 2009, pp. 119-142, ISSN: 0082-5638 doi: $10.3989 /$ tp.2009.09023 


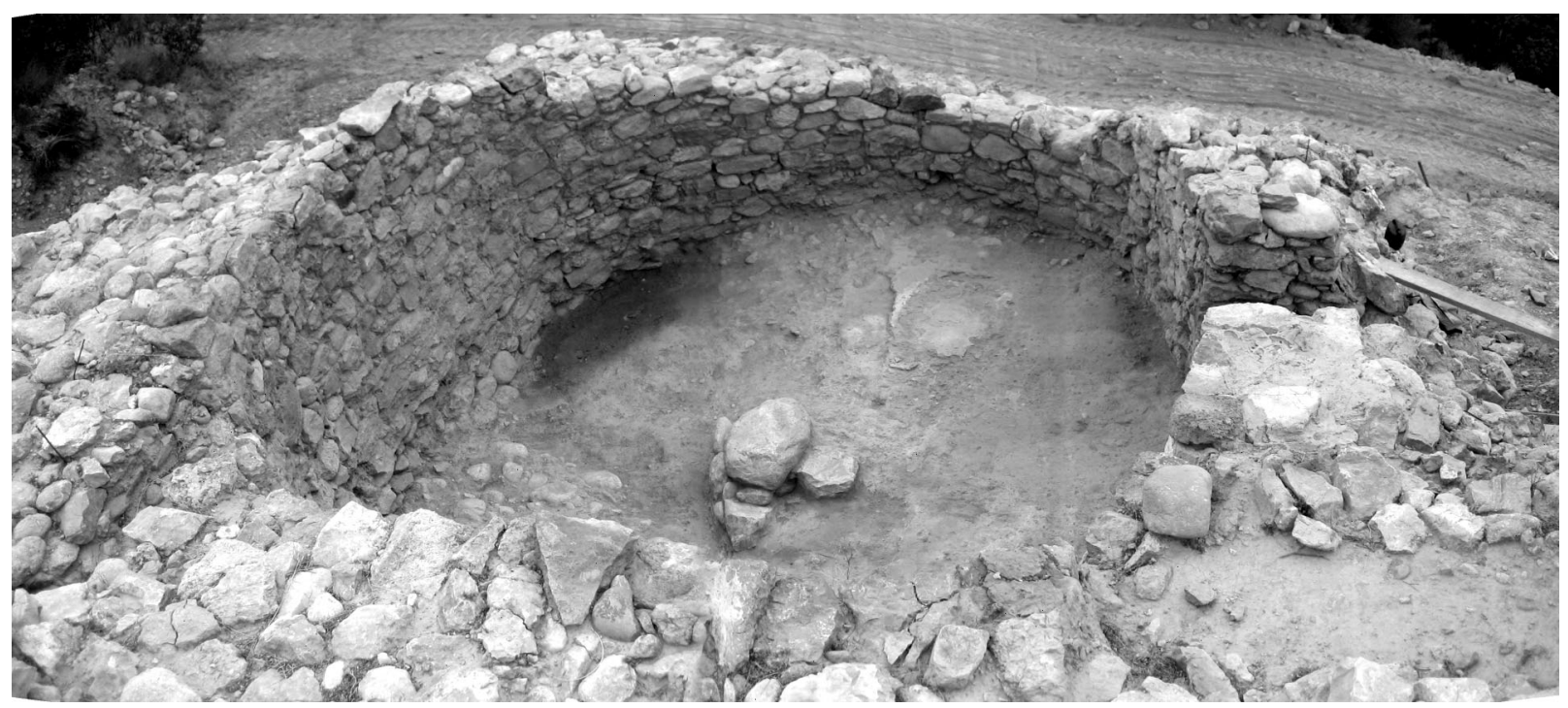

Lám. III. Torre T3 del asentamiento de L’Assut (Tivenys, Tarragona).

utilizado en este espacio de hábitat, se localiza la UE 1312, un pavimento inmediatamente anterior que tiene un hogar asociado (UE 1317). La base de este fuego se dispone sobre la UE 1318, un nivel de uso que cubre un estrato de preparación que nivela el espacio interior de la torre, compuesto por tierra y piedras que forma la UE 1314. Por debajo de ésta se encuentra ya el estrato de nivelación y relleno, UE 1313, situado sobre el terreno natural (UE 1315).

A nivel constructivo, existen diversos elementos que merecen una especial atención. En primer lugar, la existencia de un enlucido (UE 1307) que cubriría las paredes, localizado en contacto con las UE 1306 y 1308 siguiendo el perímetro murario. Se trata de un sedimento amarillento que se sitúa directamente sobre el último pavimento que estuvo en uso antes del abandono del recinto.

En el centro de la habitación encontramos, carbonizado pero perfectamente conservado, el pilar central que soportaba la viga sobre la cual se apoyaban las traviesas que formaban la estructura que sostenía el techo del primer piso. Este pilar, de madera de pino (Pinus, cf. halepensis), presentaba una sección cuadrangular finalizando en su parte superior mediante una abertura de encaje en forma de $\mathrm{U}$, donde se insertaba el fuste travesero. El resto de vigas se acoplaban en la pared de la torre a través de unas oberturas situadas a intervalos regulares y a una misma altura, que penetraban entre 20 y $50 \mathrm{~cm}$ en la cara interna del muro perimetral. El pilar central se apoyaba sobre una piedra calcárea (UE 1310) de tamaño considerable $(0,40$ por $0,60 \mathrm{~m})$, calzada mediante piedras más pequeñas.

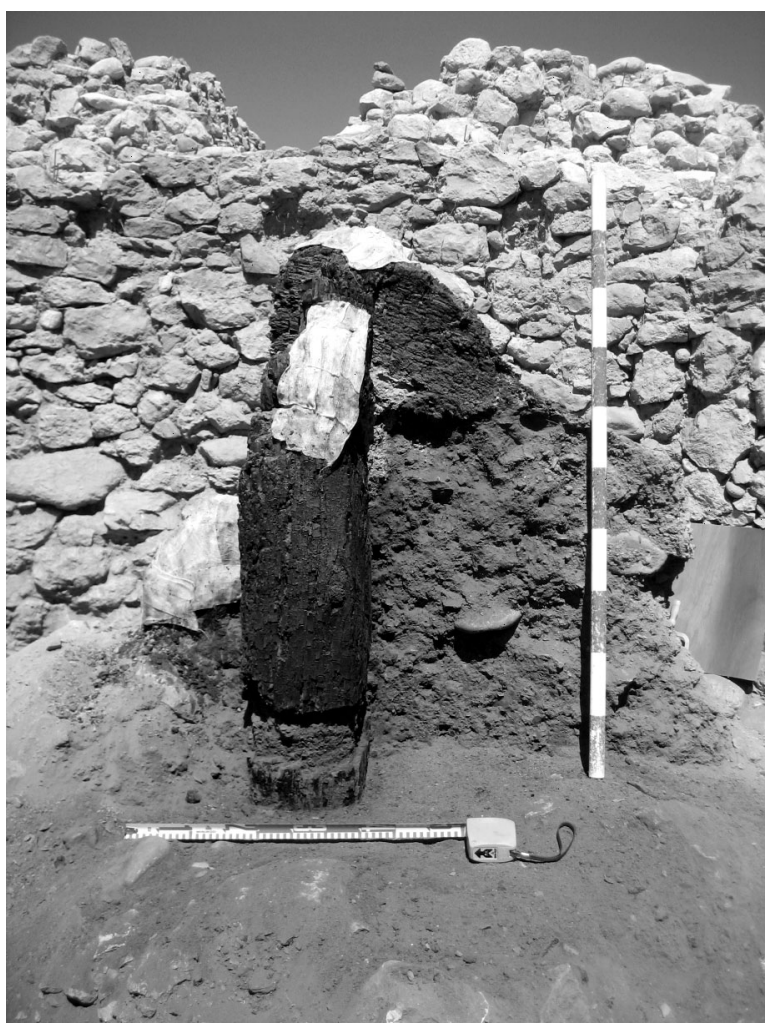

Lám. IV. Pilar central de la torre T3 del asentamiento de L’Assut (Tivenys, Tarragona).

T. P., 66, N. ${ }^{\circ} 2$, julio-diciembre 2009, pp. 119-142, ISSN: 0082-5638 doi: $10.3989 /$ tp.2009.09023 


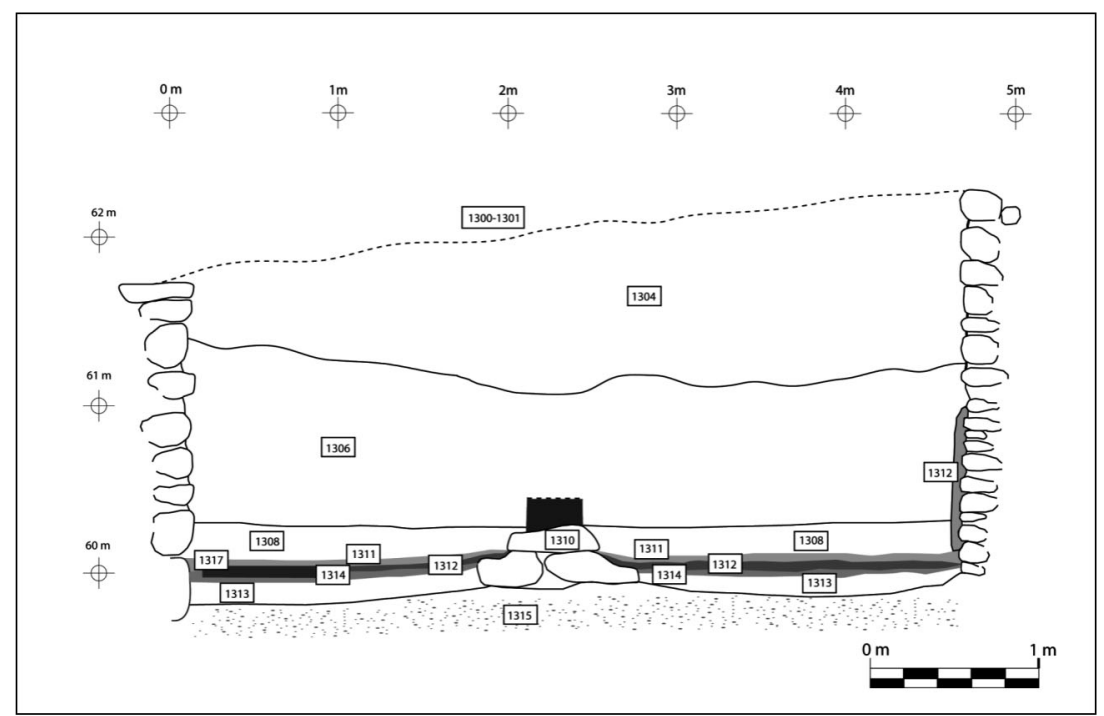

Fig. 6. Sección de la torre T3 del asentamiento de L'Assut (Tivenys, Tarragona) con detalle de las Unidades Estratigráficas.

El acceso al interior de la torre se efectuaba a través de una puerta (UE 1302) orientada hacia el suroeste, que parece quedar alineada con el último espacio de uso, si bien estaría ligeramente elevada respecto a los pavimentos de épocas anteriores. La puerta tendría una luz de no más de $0,70 \mathrm{~m}$ en su punto más ancho, y su suelo está formado por un enlosado de piedra, asociado al muro perimetral.

Por lo que se refiere al número de pisos y a la cubierta del edificio, el relleno de la torre no puede provenir de otro lugar que no sea el derrumbe del mismo y la sedimentación de los restos que formaban los ámbitos superiores. A una altura aproximada de dos metros respecto al último pavimento de uso encontramos, como ya hemos indicado, una serie de agujeros que nos indican la disposición del entramado de las vigas que sostenían el techo del primer piso. Si consideramos una altura parecida para este primer piso en relación a la planta baja, tendríamos una altura de unos cuatro metros, debido al desnivel. El espesor de los muros perimetrales nos permite plantear la hipótesis de la existencia de otro piso por encima, es decir, una segunda planta que podría elevar la altura total de la torre, desde el punto más alto del cerro, hasta como mínimo los seis metros.

Sobre el techo del edificio, no hay actualmente ningún dato que nos permita apuntar sus características. Podría tratarse, igual que se ha propuesto para el Tossal Montanyés, un techo-te- rraza plano, común en el Mediterráneo, con o sin un reborde construido a modo de parapeto (Belarte 2006: 44-45); en todo caso, un techo de estas características debería tener un buen drenaje con desagües laterales que no afectaran a la estructura, para evitar el embalse de agua de lluvia que podría provocar su ruina.

Todo este espacio interior presentaba, como ya hemos indicado, las señales de haber sufrido un violento incendio que provocó su abandono. Si bien este hecho ha permitido recuperar buena parte del mobiliario cerámico y metálico que se encontraba en el interior de la torre en el momento de su derrumbe, fue de tal magnitud que hizo estallar las piedras de las paredes, desmantelando los elementos arquitectónicos y enmascarándolos de tal manera que en algún caso se hace difícil distinguir unos de otros, siendo así que las piezas de barro, las tobas de adobe que posiblemente conformaban las paredes del piso o pisos superiores, pasaron a rellenar el interior de la torre, de la misma manera que techos, enlucidos y otros elementos de tipo arquitectónico.

\section{FASES DE OCUPACIÓN DE T3}

Tal como ya hemos indicado, la ocupación de la torre T3 del asentamiento de L'Assut se dilata a lo largo de aproximadamente 350 años. Esta perduración en el espacio y en el tiempo, así como su 
repentina destrucción, influyen en la dificultad de interpretación de la funcionalidad del espacio interior, siendo como es lógico la última fase la que presenta los elementos que permiten efectuar una aproximación a su estructuración u organización interna.

De este modo, debemos indicar que la datación de su construcción está asociada a la presencia de algunos elementos materiales, básicamente cerámicos, y sobre todo a los diferentes análisis radio-carbónicos que se han efectuado del pilar central de la misma, elemento relacionado directamente con la construcción del edificio, pues es el principal soporte de los pisos superiores.

En base a la cerámica recuperada durante la intervención en el interior de la torre, se puede plantear una secuencia ocupacional cronológicamente decreciente, en la que destacan para los momentos más arcaicos la presencia de un conjunto formado por algunos fragmentos informes de ánfora fenicia procedente del sur peninsular, así como por un borde de ánfora del mismo tipo, Vuillemot R-1, T10-1.2.1 (Ramon 1995). Estos elementos irían acompañados por diversos fragmentos de cerámica a mano, destacando las jarras decoradas con cordones incisos y los pequeños vasos bruñidos. No obstante, la mayoría de cerámicas exhumadas de esta fase corresponden a los platos carenados de borde exvasado, muy similares a los documentados en contextos regionales del área del Ebro durante la Primera Edad del Hierro, como es el caso del yacimiento del Turó del Calvari (Vilalba dels Arcs) (Bea y Diloli 2005), Sant Jaume (Alcanar) (1) o Barranc de Gàfols (Ginestar) (Sanmartí et al. 2000), así como en necrópolis tumulares, como el Coll del Moro (Gandesa) (Rafel 1991) o el Barranc de Sant Cristòfol (Maçalió) (Rafel 2003).

De un momento de ocupación posterior destacan una serie de materiales cerámicos de importación, localizados al igual que los anteriores fuera de un contexto estratigráfico ordenado, correspondientes a un horizonte enmarcable en el momento de transición entre los siglos VI-V a.n.e., como son el borde de un plato de cerámica gris monocroma de occidente de tipo à marli, datada entre 575-450 a.n.e. (Arcelin 1978) y el asa de una producción anfórica griega indeterminada,

(1) D. García, El poblament del primer ferro a les terres del Sènia. Els assentaments de la Moleta del Remei, Sant Jaume, La Ferradura i la Cogula durant els segles VII $i$ VI a.n.e., Tesis doctoral inédita. Universitat de Barcelona. 2005. pero que se podría corresponder con la tipología ática de las ánforas à la brosse. Se trata, en todo caso, de recipientes de origen griego, la llegada de los cuales debemos vincular a la expansión que experimenta el comercio foceo-masaliota a partir de mediados del siglo VI a.n.e.

Este conjunto de cerámicas podrían asociarse, al igual que las anteriores, al momento de construcción del edificio, si bien como hemos indicado se trata de elementos descontextualizados, pues aparecen coligados a niveles de ocupación posteriores, formando parte de estratos que se han interpretado como reformas estructurales.

Ya en la fase siguiente, la cerámica ibérica se erige como el máximo exponente vascular de los restos recuperados en el interior de la torre. A nivel cuantitativo, en los niveles UE 1304, 1306 y 1308 , el porcentaje de vasos ibéricos es del $88,2 \%$, con un $79,4 \%$ (54 individuos diferenciados) de vajilla y un 20,6 \% (6 individuos) de ánforas, mientras que entre las importaciones, que constituyen el 11,8\% del total (7 individuos), aproximadamente un $60 \%$ son elementos de vajilla y un $40 \%$ ánforas.

Tipológicamente, en el conjunto de la cerámica ibérica es interesante destacar la presencia de un grupo compuesto principalmente por jarras y platos que exhiben una decoración pictórica a base de amplias franjas de color rojo vinoso y en algunos casos líneas de goteo verticales, unas características habituales en este territorio en producciones antiguas; no obstante, sus pastas, compactas, no se corresponden con las características técnicas de las primeras producciones ibéricas del área del Ebro, por tanto, podría tratarse de una producción importada. Entre las formas localizadas destacan por su cuantía los pithiskoi, documentándose también los platos, cuencos, tapadoras, vasos y la presencia tardía de kalathoi.

Los materiales de importación están representados principalmente por las ánforas, las más antiguas procedentes de la órbita feno-púnica, con algunos fragmentos localizados en los niveles de derrumbe; ya de época ibérica un ejemplar posiblemente púnico-ebusitano $\mathrm{y}$, en un momento avanzado una ánfora greco-itálica tipo Lyding-Will C (Lyding Will 1982), que podemos fechar con total seguridad hacia finales del siglo III a.n.e. o inicios del II a.n.e., recuperada descansando sobre el pilar central y fragmentada por el derrumbe del techo que la sepultó, proporcionándonos así una datación muy concreta sobre el momento de destrucción del edificio. 


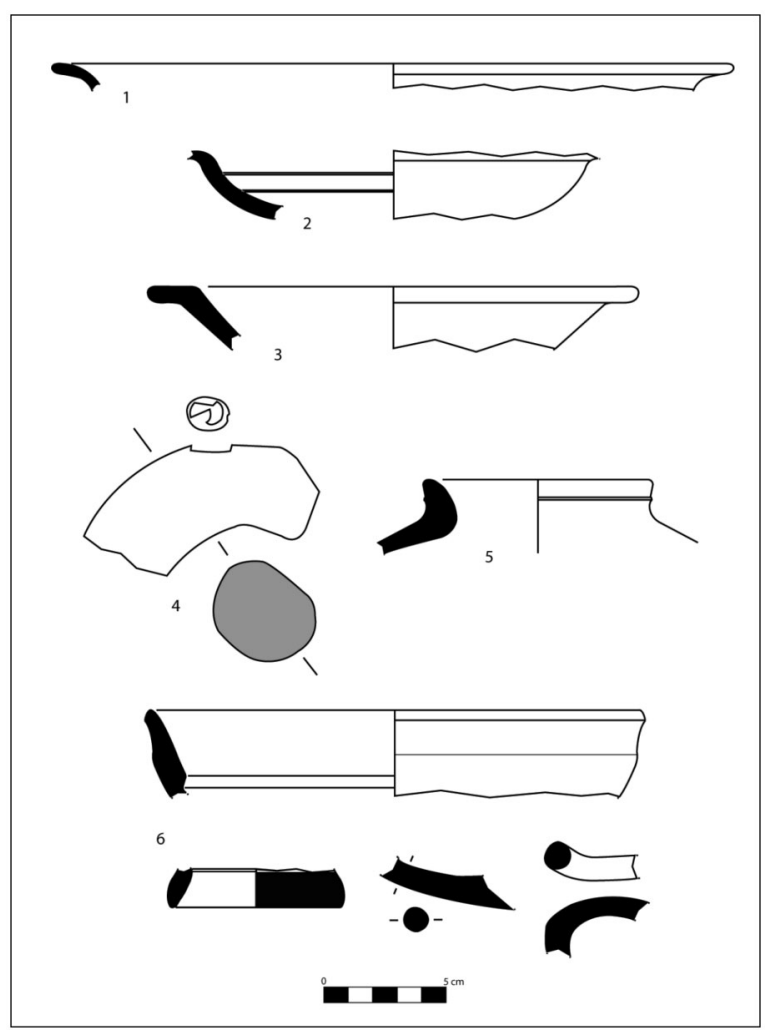

Fig. 7. Materiales representativos de la primera fase de T3 del asentamiento de L'Assut (Tivenys, Tarragona): 1 y 2.- Platos bruñidos; 3.- Plato de cerámica gris monocroma; 4.- Ánfora griega; 5.- Ánfora fenicia T10.1.2.1. Cerámicas áticas de la fase de T3 correspondiente al Ibérico Pleno: 6.
Otros materiales de importación los forman las cerámicas de barniz negro, destacando la presencia en la UE 1314 de 10 fragmentos de cerámica ática: un borde y una carena de un kylix tipo stemless inset lip, dos fragmentos de asa de kylix, pertenecientes a dos vasos diferentes, un fragmento del pie de una copa, posiblemente también un kylix, un fragmento de la pared de un kylix, en el que se observa la ranura anular del pie y un fragmento decorado con figuras rojas, que recuerda el estilo Saint-Valentin. Estos elementos, que podrían formar parte de al menos dos vasos datables durante la segunda mitad del siglo $\mathrm{V}$ a.n.e., aparecieron asociados al nivel sobre el que se sitúa el hogar 1317, y nos indicarían una fase de uso de la torre cercana o incluso coetánea de la construcción del sistema defensivo y por ende del poblado ibérico.

Otros elementos de vajilla recuperados proceden del ámbito púnico, siendo en los niveles del $\mathrm{V}$ al III a.n.e. donde estos vasos son más importantes, destacando un borde de mortero, un plato $\mathrm{y}$ un pequeño vaso.

Con estos datos, es difícil precisar el momento de construcción de la torre T3, pues el estrato mejor identificado es el correspondiente al siglo $\mathrm{V}$ a.n.e. Sin embargo, la presencia de los materiales pertenecientes a un momento anterior, recuperados en el interior del edificio, indica la posibilidad de su edificación en un momento previo al nivel en el que se han recuperado las cerámicas áticas.

\begin{tabular}{|l|r|r|r|r|r|r|r|}
\hline & $\mathbf{1 3 0 4}$ & $\mathbf{1 3 0 6}$ & $\mathbf{1 3 0 8}$ & $\mathbf{1 3 1 1 - 1 2}$ & $\mathbf{1 3 1 3 - 1 4}$ & Total & Total Rev \\
\hline COIT & 6 & 24 & 1 & 8 & 16 & 55 & 55 \\
CRIT & 1 & 2 & & 2 & 2 & 7 & 6 \\
CIM & 4 & 13 & 3 & 4 & 3 & 27 & 27 \\
COP & & 1 & & & 3 & 4 & 4 \\
BNA & & 1 & & & 2 & 3 & 3 \\
BNIN & 1 & 4 & 1 & 2 & 1 & 1 & 1 \\
AI & 1 & 1 & & & & 10 & 10 \\
AF & 1 & 1 & 1 & 1 & & 1 & 1 \\
ATF & & 1 & 1 & & & 3 & 1 \\
AP & 1 & 1 & 1 & & & 3 & 1 \\
AGI & 15 & 50 & 8 & 17 & 29 & 119 & 112 \\
AIN & & & & & & 2 \\
& & & & & & & \\
\end{tabular}

Tab. 1. Cuantificación del número de individuos cerámicos recuperados en el interior de la torre T3 de L'Assut. COIT, cerámica oxidada ibérica a torno; CRIT, cerámica reductora ibérica a torno; CIM, cerámica ibérica no torneada; COP, cerámica oxidada púnica; BNA, barniz negro ático; BNIN, barniz negro indeterminado; AI, ánfora ibérica; AF, ánfora fenicia; ATF, ánfora de tipo fenicio; AP, ánfora púnica; AGI, ánfora greco-itálica; AIN, ánfora indeterminada. 
Respecto a las dataciones radiocarbónicas, se han efectuado cuatro análisis con muestras extraídas del pilar central de la torre. Este elemento, que apareció carbonizado in situ conservando perfectamente su forma y tamaño, pues el derrumbe del piso superior lo sepultó manteniéndolo erguido, estaba formado por dos piezas diferentes; la superior (1350), presentaba una sección cuadrada, mientras que la inferior (1354), más dañada, podría tener una sección un poco más irregular. Su unión se producía a partir de la preparación de una ensambladura en ambas piezas, en forma escalonada, que permitía su perfecta conexión, posiblemente con la ayuda de cuerdas, tal y como se hacía en los mástiles de algunas embarcaciones antiguas.

Las dos muestras analizadas del fragmento 1350, en laboratorios diferentes, Beta Analytic Radiocarbon Dating Laboratory de Miami (Florida) y el Laboratori de datació per Radiocarboni de la Universitat de Barcelona, han proporcionado los siguientes resultados de datación convencional (Tab. 2).

A partir de estos datos se observa como hay una diferencia substancial entre las dos muestras, destacando el desplazamiento cronológico de los resultados obtenidos por el laboratorio de Miami de los datos derivados de la datación tipológica.

En cuanto a la muestra 1354, procedente de la parte inferior de la columna, los análisis se han realizado también en dos laboratorios diferentes, la primera muestra en el Radiocarbon Dating Laboratory de la Lunds Universitet de Suecia y la segunda en el Laboratori de datació per Radiocarboni de la Universitat de Barcelona, con los siguientes resultados (Tab. 3).
En este caso la diferencia, si bien no tan destacada como en la prueba anterior (UE 1350), presenta también cierta desviación de uno a otro laboratorio.

Si descartamos los resultados proporcionados por Beta Analytic, que son los más discrepantes respecto al total, podemos proponer, a partir de estos datos, un marco cronológico para la construcción del edificio que oscilaría, en sus extremos superior e inferior, entre mediados del siglo VII a.n.e. y finales del siglo VI a.n.e., con una aproximación media al intervalo situada a inicios del siglo VI a.n.e.

De todos modos, no podemos obviar la problemática derivada del uso de muestras procedentes del mobiliario arquitectónico para efectuar las dataciones radiocarbónicas que nos determinen la fecha de edificación de la residencia, pues desconocemos el margen temporal transcurrido entre la muerte del vegetal y el uso del objeto; en todo caso, asociando estos datos a la determinación cronológica de los materiales cerámicos más antiguos recuperados en el interior de la torre, podemos proponer un momento de construcción para este edificio durante el primer cuarto del siglo VI a.n.e.

Los resultados radiocarbónicos calibrados son más confusos si los relacionamos con la cronología propuesta tradicionalmente por la tipología de los ítems cerámicos recuperados en el interior del edificio, de manera que pensamos que su uso se debe mantener como provisional hasta que, como ya han indicado otros autores, no se efectúe un debate sobre la fiabilidad de los métodos radiocarbónicos y tipológicos que permita redefinir la cronología de la Protohistoria peninsular (Molinos y Ruiz 2007: 54).

\begin{tabular}{|lllllr|}
\hline & Laboratorio & UE & Material & Datación C14 BP & C14 cal. (2s) BC \\
\hline a) & Beta-237599 & 1350 & Madera Pinus $h$. & $2770 \pm 40$ BP & $\begin{array}{r}1010-820 / \text { pro. } 912 \\
\text { b) }\end{array}$ \\
\hline
\end{tabular}

Tab. 2 .

\begin{tabular}{|llllll|}
\hline & Laboratorio & UE & Material & Datación C14 BP & C14 cal. (2s) BC \\
\hline a) & LuS 7769 & 1354 & Madera Pinus $h$. & $2481 \pm 30$ BP & $770-500 /$ pro. 642 \\
b) UBAR-992 & 1354 & Madera Pinus $h$. & $2570 \pm 35$ BP & $810-742 /$ pro. 788 \\
\hline
\end{tabular}

Tab. 3 . 


\section{INTERPRETACIÓN DE T3}

La tipología constructiva de la torre de L'Assut nos muestra una arquitectura singular distinta de la que encontramos representada en otros establecimientos de esta época en la misma región: se trata como hemos descrito, de un edificio aislado, de planta circular, construido con una intencionalidad defensiva y de control territorial, pero integrando también una función doméstica. Si buscamos paralelos en esta área geográfica de forma amplia, Tossal Montanyés, en Valdetormo, o La Guàrdia, en Alcorisa, parecen ser los modelos más cercanos a la torre T3 de L'Assut, sin desestimar los momentos más antiguos de la torre del poblado ibérico del Coll del Moro (Gandesa, Terra Alta), que se edificaría también probablemente durante la primera mitad del siglo VI a.n.e. La existencia de estos espacios arquitectónicos dotados de una singularidad tan visible, que los diferencia de otros tipos de hábitat de esta fase histórica, tanto por la forma como por el fondo, se ha querido explicar como la voluntad de un sector social elitista, que adquiere o confirma unos privilegios durante el siglo VI a.n.e. y que pretende diferenciar su residencia del resto de espacios habitados mediante el uso de una arquitectura simbólica (Moret et al. 2006: 244). Se trataría pues de la plasmación física de una ruptura social asociada al surgimiento de unas élites protoaristocráticas que utilizarían este, entre otros medios, para representar su poder sobre el resto de la sociedad, materializando su autoridad con un modelo arquitectónico de prestigio. Se trata de un momento en el que los sectores emergentes se están consolidando y la representación de su autoridad precisa de nuevos parámetros, superada la etapa anterior, más materialista, de tipo ideológico o representativo, como puede ser la segregación doméstica del resto de la comunidad. En palabras de N. Rafel (2006: 139) "son estos personajes los que habitan en estas residencias aisladas y los que se entierran en sepulcros con objetos de prestigio", pues también en este momento el mundo funerario sufrirá una transformación formal y de contenido, especialmente en los ajuares, que integrarán elementos de distinción social, prestigio y sobre todo poder coercitivo, como por ejemplo las armas, poco presentes en las etapas anteriores.

La torre T3 de L'Assut ejemplifica así desde la primera mitad del siglo VI a.n.e. hasta su integración dentro del sistema defensivo del poblado, una residencia fortificada, posiblemente ocupada por miembros de un grupo de poder que se gestaría en este momento y que controlaría el entorno circundante y sus medios de producción e intercambio.

La segunda fase de ocupación de este espacio se iniciaría con la planificación urbanística que habría de servir para edificar el poblado ibérico de L'Assut. A partir de mediados del siglo V a.n.e., el cerro de L'Assut se modificará profundamente por la construcción de un núcleo de hábitat que supera los $3.500 \mathrm{~m}^{2}$ de superficie ocupada, si bien la torre T3 se conservará sin modificaciones estructurales distinguibles, integrándose dentro del complejo defensivo que protegerá el acceso al asentamiento.

La nueva fortificación, situada en la parte más alta del poblado, se erige a partir de la presencia de la torre, envolviéndola mediante muros adosados, adquiriendo así un carácter inexpugnable y permitiendo la pervivencia de un espacio simbólico, asociado a una de las zonas más importantes del asentamiento, la destinada a su defensa. De hecho, la construcción del sistema defensivo se efectúa segmentado el área fortificada de la zona habitacional mediante un muro, que si bien se integra en el urbanismo del poblado, separa claramente las dos zonas, escenificando la existencia de una ciudadela interna en el seno del oppidum, en la cual la torre T3 serviría tanto para dominar visualmente el exterior como para controlar el interior del núcleo habitado, acentuando su papel fundamental de centro de poder. En este sentido, hay una clara asociación entre el espacio residencial del grupo dominante y el sistema defensivo, que, en última instancia, depende de este grupo como máximo responsable de la protección del poblado.

La duración de esta fase habitacional sería aproximadamente de dos siglos y medio. A finales del siglo III a.n.e. se produce, como ya hemos indicado, un violento incendio que únicamente afecta a la torre T3 poniendo fin a su ocupación, sin propagarse hacia ningún otro elemento constructivo del poblado, que continúa habitado durante al menos 100 años más.

De hecho, es este último momento de ocupación el que ha aportado más datos y el que nos permite esbozar una hipótesis sobre el motivo de su destrucción y abandono. La reconstrucción que hemos llevado a cabo del espacio interior nos muestra, para este último momento de uso, una habitación pavimentada, con un pilar central que soportaría el techo del piso superior, al cual se 
accedería mediante una escalera de mano; a la izquierda de la entrada a la torre se localiza una estructura sobreelevada respecto al pavimento, construida con piedra y de planta semicircular, que estaría probablemente relacionada con labores de combustión, si bien la cremación del edificio dificulta su interpretación. Sobre esta estructura se localizaron varias varillas que se han identificado como uno o diversos asadores, hecho que otorgaría a este espacio interior una funcionalidad relacionada con la cremación.

Junto a esta zona han aparecido algunos fragmentos muy bien conservados de corcho, elemento que en otros asentamientos se ha interpretado como un posible impermeabilizante de los techos (Contreras et al. 1996; Rivera 2007), sin que podamos excluir su uso en otros parámetros constructivos o incluso formando parte de muebles,

A
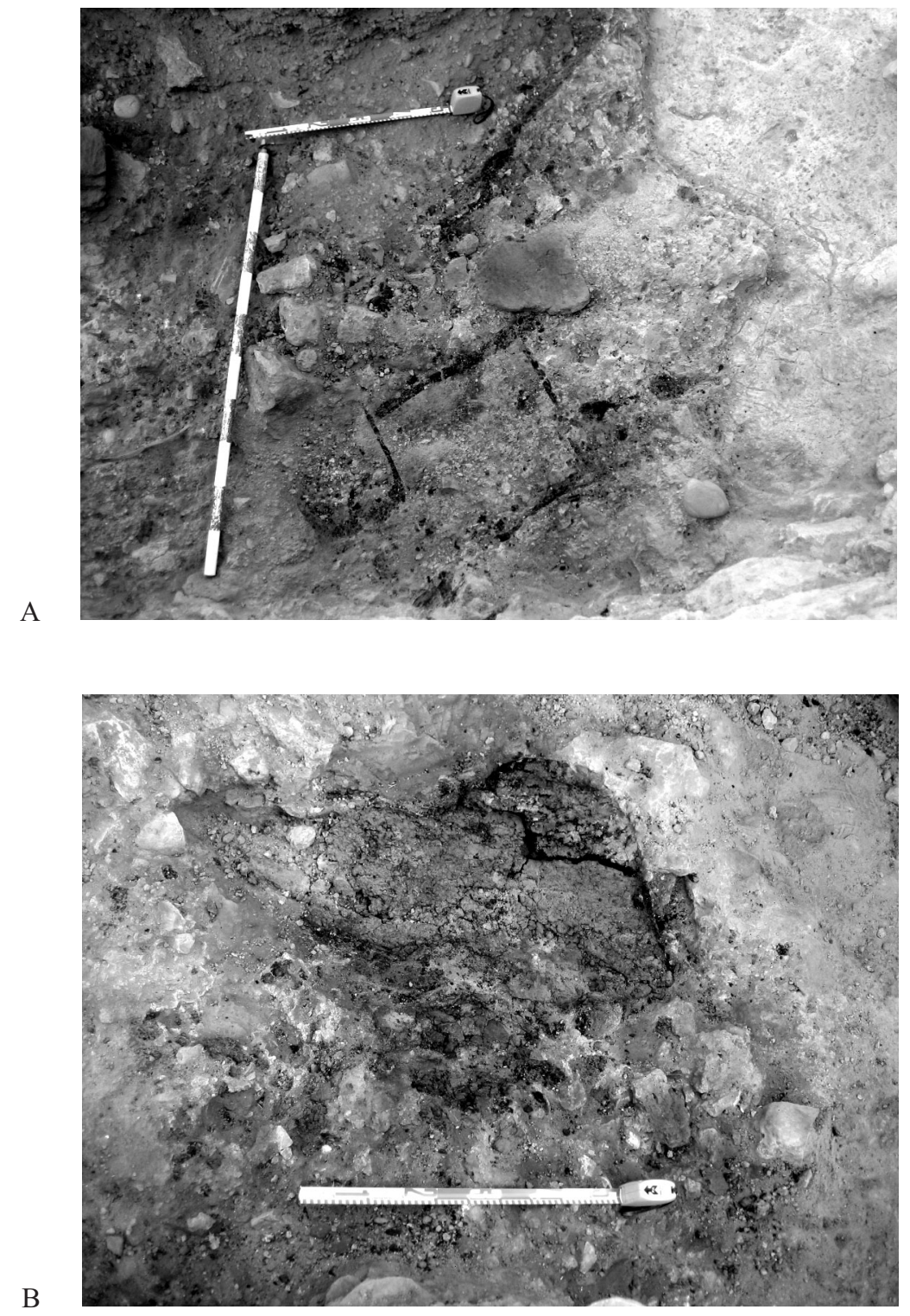

Lám. V. Torre T3 de L'Assut (Tivenys, Tarragona). A: Uno de los elementos de madera carbonizada recuperados, posiblemente una escalera de mano. B: Detalle de un fragmento de corcho carbonizado.

T. P., 66, N. ${ }^{\circ} 2$, julio-diciembre 2009, pp. 119-142, ISSN: 0082-5638 doi: $10.3989 /$ tp.2009.09023 
como se propone en el caso del poblado argárico de Peñalosa (Baños de la Encina, Jaén) (Contreras et al. 1996). En todo caso, debemos destacar que el Quercus suber es una especie que no está representada en el ecosistema del bajo Ebro y que se trata de un elemento adquirido mediante el comercio a media distancia, pues los bosques de alcornoques más cercanos se encuentran en el norte catalán o en la Sierra de Espadán, en Castellón.

Por otra parte, el conjunto material más interesante procedente del interior de la torre posiblemente lo formen los objetos metálicos. Sobre el pavimento, UE 1311, en el estrato que lo cubre, UE 1308, o en el superior a este, UE 1306, que podría formar parte del piso superior, han aparecido la mayor parte de los elementos de metal que se han recuperado durante el proceso de excavación. Entre estos hemos diferenciado cuatro grandes grupos a partir de su funcionalidad: los relacionados con las labores económicas, especialmente agrícolas, destacando dos podaderas pequeñas y una azadilla, o diversas láminas de plomo enrolladas, posibles plomos de red que podríamos vincular con la pesca fluvial, al estilo de las localizadas en el asentamiento vecino de Les Planetes (Tortosa, Baix Ebre) (Diloli et al. 2003). Otro grupo de metales lo forman los elementos de uso doméstico, como las varillas de asador, las anillas, clavos, bisagras, placas de hierro, bronce y plomo y grapas de hierro. Por otro lado encontramos los elementos de uso personal, entre los

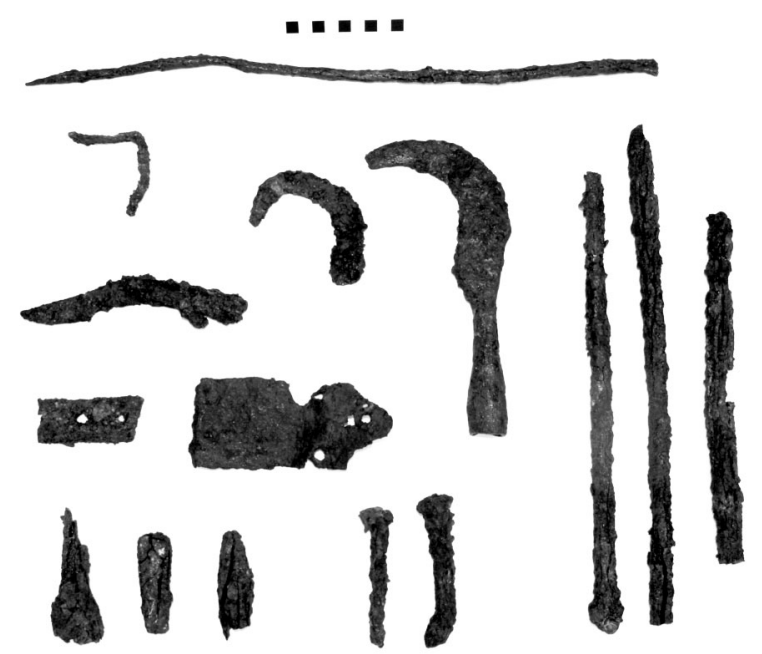

Lám. VI. Parte del conjunto de elementos de metal recuperados en el interior de T3 de L'Assut (Tivenys, Tarragona). que sobresalen una lanza, un soliferreum, un cuchillo afalcatado, dos fíbulas, una placa de adorno que podría formar parte de un cinturón o de una funda de espada y, por último, una agrupación de otros ítems diversos, destacando la presencia de una moneda muy deteriorada por el efecto del fuego. En el caso de la fíbulas, se trata de dos ejemplares de resorte bilateral, uno de bronce y otro de hierro, siendo la mejor conservada la de bronce, que presenta el pie elevado con botón terminal y un arco de sección circular y cuerda externa, que se podría datar durante el siglo VI a.n.e., a pesar de haberse localizado en un nivel fechado con toda seguridad durante los últimos años del siglo III a.n.e. La cuerda interna parece poder emparentar la fíbula de la torre $\mathrm{T} 3$ con las aparecidas en contextos meridionales peninsulares, más antiguos, si bien el arco de sección circular la acercaría a la segunda mitad del siglo VI a.n.e. Ejemplos contextualizados de estas piezas los encontramos en Corno-Lauzo (Pouzols-Minervois, Llenguadoc), con una fíbula similar fechada en la segunda mitad del siglo VI

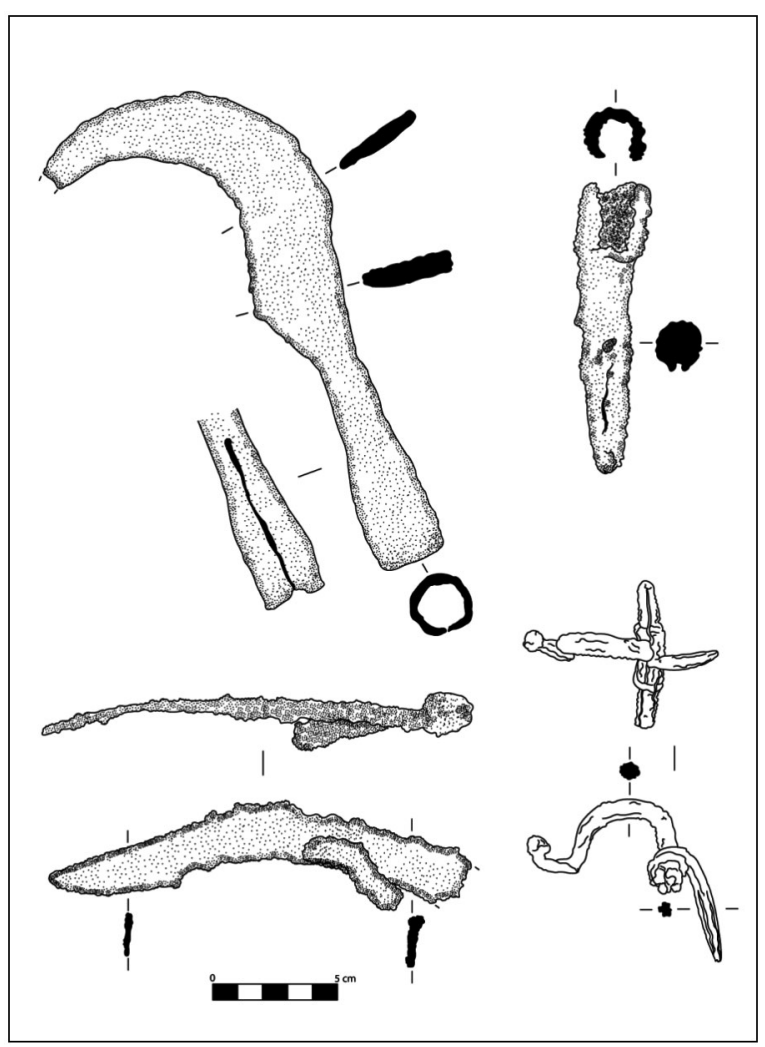

Fig. 8. Parte del conjunto de metales aparecido en T3 de L'Assut (Tivenys, Tarragona). 
a.n.e. a partir de su asociación a un kylix ático del tipo de los "pequeños maestros" encuadrable entre el 550 y el 540 a.n.e. y de una copa jonia B-2 (Pons 1984), mientras que en el curso inferior del Ebro, hallaríamos paralelos en la necrópolis de Mas de Mussols datables durante la segunda mitad del siglo VI a.n.e., de forma que proponemos para el ejemplar de L'Assut una cronología situada a grosso modo entre el 550 y el 500 a.n.e.

En cuanto a los materiales cerámicos, cabe diferenciar los elementos de vajilla de otras producciones cerámicas no vasculares, como un conjunto compuesto por casi un centenar de pesas de telar (pondera), que habrían formado parte de uno o más telares ubicados en el piso superior de la torre. Elaborados con arcilla depurada, podemos diferenciar dos módulos distintos a partir de su peso sin relación con la forma: el primero, con un $80 \%$ de ejemplares, sería del tipo medio, con un peso que oscilaría entre los $275 \mathrm{y}$ los 400 g. Otro grupo estaría formado por los pondera de mayor volumen, encuadrados entre los 800 y los $1.000 \mathrm{~g}$. Este grupo es más heterogéneo que el anterior, pues si bien el pondus mayor llega hasta los $1.025 \mathrm{~g}$, hay otros que no alcanzan los $800 \mathrm{~g}$, aunque se encuentran mayoritariamente rotos, hecho que puede influir en sus medidas.

Debemos destacar que se trata de dos módulos relacionables, pues dos pesos del grupo A pueden utilizarse para ejercer la misma tensión que un pondus del tipo B. La utilización de uno de los tipos o su combinación se relacionaría con el elemento textil que se pretendiera confeccionar. De hecho debemos valorar el peso como la característica esencial de estos elementos, pues de este depende el grado de tensión que soportan los fajos de hilos sobre los que se efectúa el tejido y el tipo de tela elaborada. Tipológicamente, hay piezas trapezoidales (Castro 1985, 1986), con medidas que oscilan aproximadamente entre los 8-12 $\mathrm{cm}$ de altura y los 6-8 $\mathrm{cm}$ de anchura y elementos de tipo cuadrangular, de tamaño parecido. Dada la similitud de formas, no es arriesgado pensar en

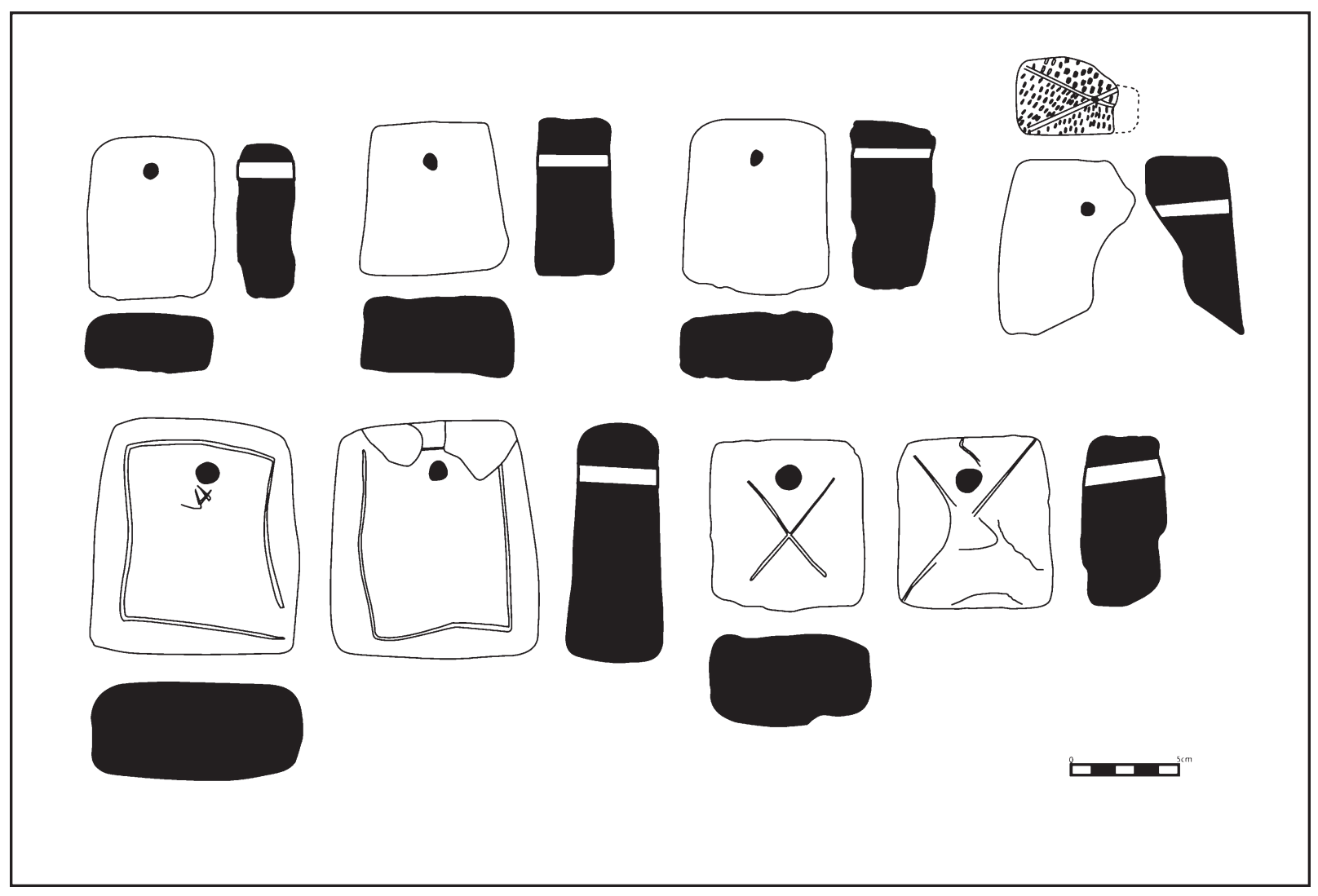

Fig. 9. Muestra de algunos pesos de telar recuperados en T3 de L'Assut (Tivenys, Tarragona).

T. P., 66, N. ${ }^{\circ}$, julio-diciembre 2009, pp. 119-142, ISSN: 0082-5638 doi: $10.3989 /$ tp.2009.09023 
la existencia de unos moldes que explicarían también el parecido de los pesos, elaborándose la pieza a partir de un bloque de arcilla del mismo tipo que la utilizada para la fabricación de las cerámicas. Por otro lado, algunos de estos elementos presentan decoraciones en la base o en la parte superior, generalmente en forma de cruz, aunque también hay ejemplares con uno de los lados decorados, generalmente con dibujos geométricos del tipo de cuadrados paralelos, o con punteados o incisiones. Se trata de un tipo de pondera habitual en los asentamientos ibéricos de la ribera del Ebro, asimilables a los documentados en el yacimiento vecino del Castellot de la Roca Roja (Be-

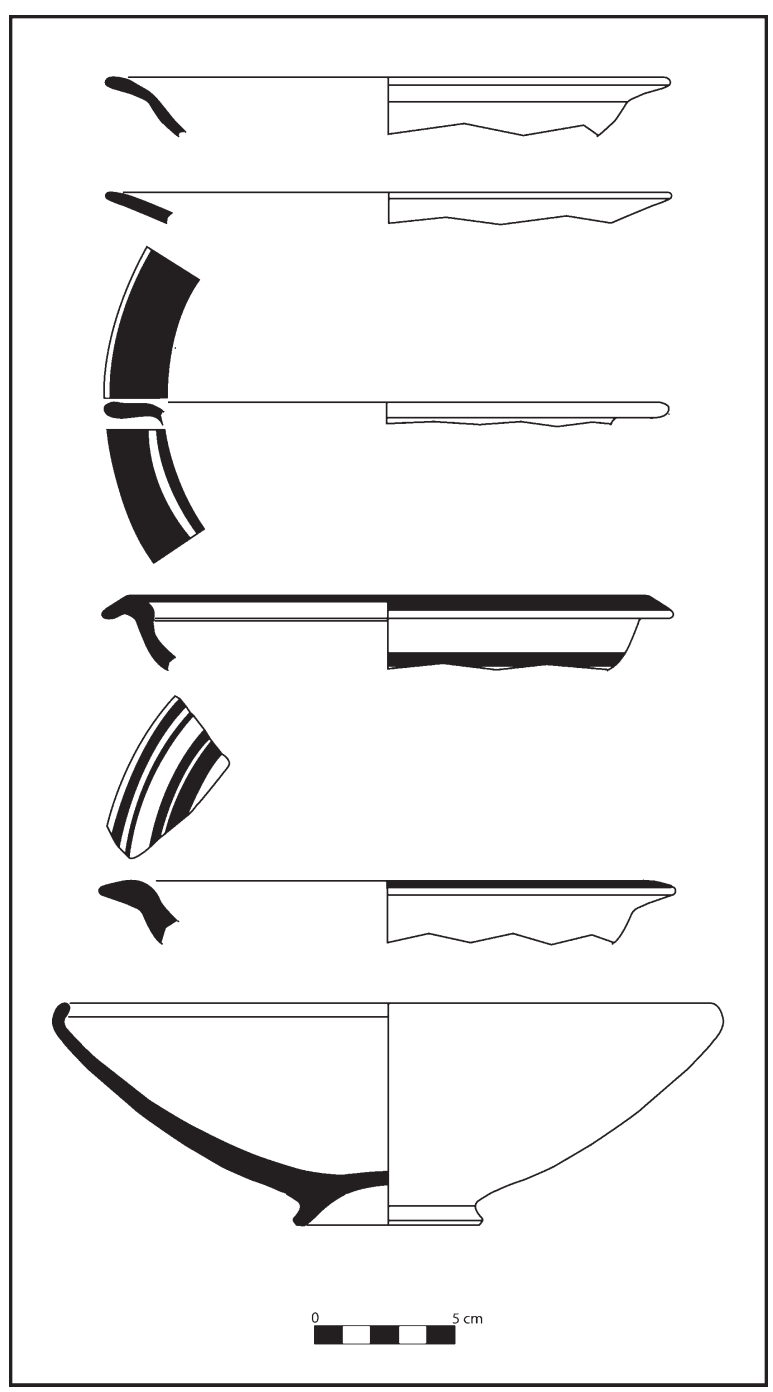

Fig. 10. Conjunto de platos ibéricos de la torre T3 de L’Assut (Tivenys, Tarragona). nifallet) (Belarte et al. 2002: 106; Fig. 20) o en el de Les Planetes (Diloli et al. 2003: 60), entre otros.

Sobre la cerámica vascular, se han exhumado diversos elementos de vajilla que ocupan, como ya hemos apuntado, un espectro cronológico bastante amplio, con producciones que engloban desde la cerámica indígena hasta algunos fragmentos de ánfora fenicia procedente del Círculo del Estrecho, la cerámica de barniz negro ático, que podríamos asociar al momento de estructuración del poblado, vasos de origen púnico o una ánfora de origen greco-itálico, del último momento de ocupación.

Entre todos estos elementos, el conjunto que destaca por su proporción es el compuesto por la vajilla ibérica, procedente sobre todo del último momento de uso del edificio: platos, cuencos, jarras, pithiskoi, ánforas, etc. Básicamente se trata de cerámicas comunes oxidadas a torno, pintadas en algún caso con motivos geométricos y con un espectro formal variado, pues hay piezas de tipología arcaica mezcladas con vasijas más modernas como el kalathoi.

La existencia de este mobiliario metálico y cerámico en la torre nos da cierta información sobre la calidad social de sus ocupantes, especialmente por la presencia de unos objetos metálicos, ya sean de hierro, bronce o plomo, de prestigio o esenciales dentro de los procesos de producción. Asimismo, las vasijas cerámicas son también in-

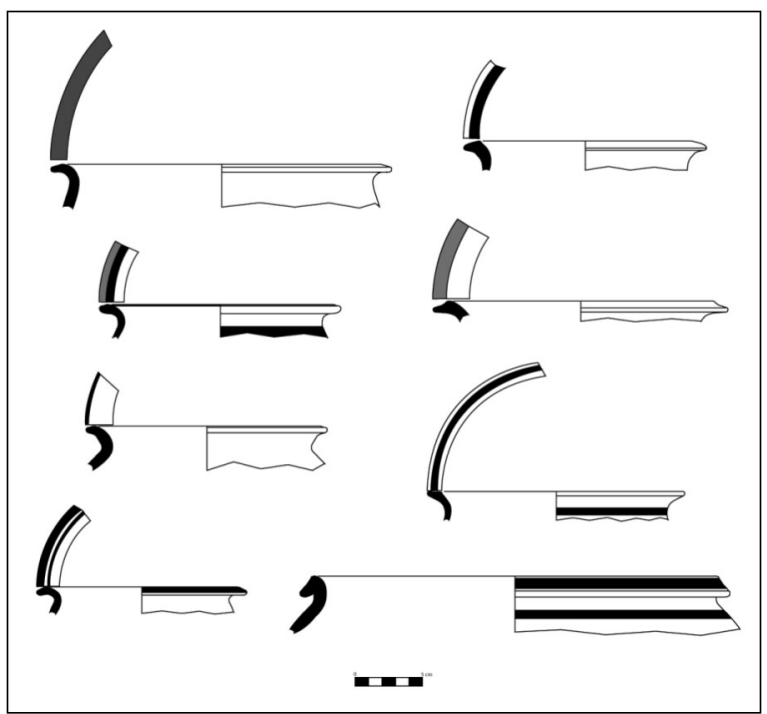

Fig. 11. Jarras de almacenaje ibéricas de la torre T3 de L’Assut (Tivenys, Tarragona). 


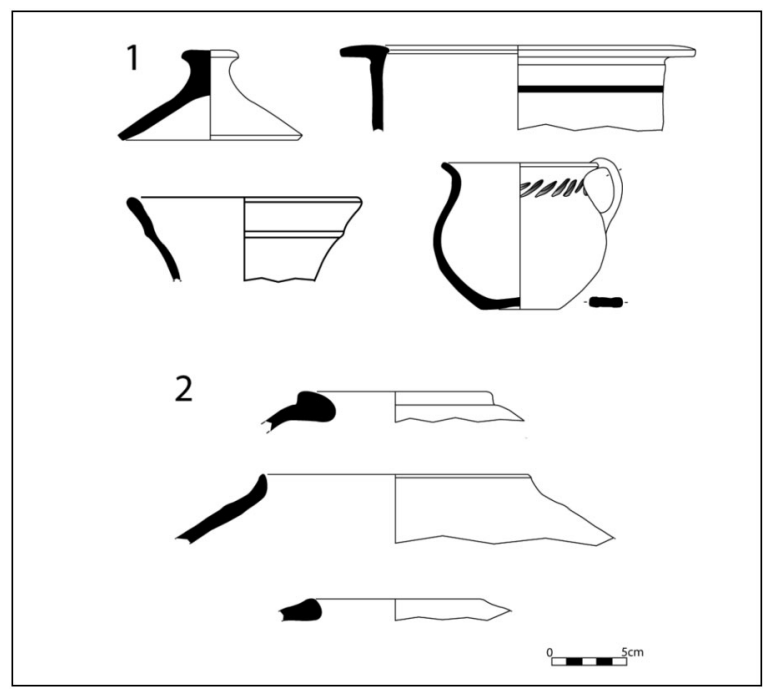

Fig. 12. 1.- Cerámica ibérica procedente del último momento de uso de la torre T3 de L'Assut (Tivenys, Tarragona): tapadora, kalathos, jarra, olla. 2.- Ánforas ibéricas.

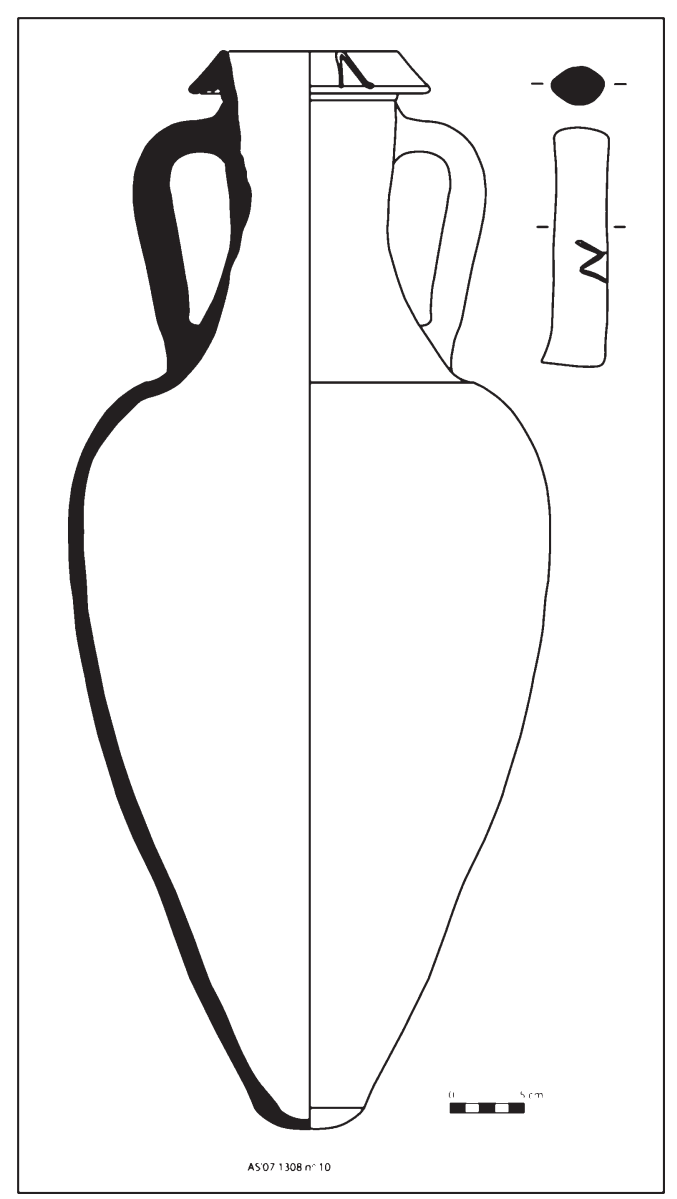

Fig. 13. Ánfora greco-itálica tipo Lyding-Will C (torre T3 de L'Assut, Tivenys, Tarragona). teresantes, con diversos vasos en uso o residuales procedentes de todo el ámbito mediterráneo. Suponemos, pues, que tanto por la situación del edificio como por la condición de los elementos recuperados en su interior, así como otros datos referentes a su devastación que explicaremos más adelante, en este espacio habitaba un grupo familiar con cierta ascendencia o autoridad sobre la comunidad.

A finales del siglo III a.n.e. o muy a principios del II a.n.e., la torre sufre, como hemos señalado, un incendio provocado que comporta su destrucción y abandono, pese a que el poblado continúa ocupado. La virulencia de la deflagración es tal que las piedras que conforman las paredes estallan, derrumbándose la estructura. Este hecho, junto con otros indicios aparecidos en el transcurso de los trabajos arqueológicos, nos indica que pese a la importancia del recinto en el conjunto del poblado, no se hizo ningún esfuerzo para apagar el fuego. Es más, ni siquiera cuando se sofocó se intentó recuperar los enseres del interior de la torre o reconstruirla. Por otro lado, a parte de su ubicación privilegiada, el material hallado en el recinto exterioriza su importancia en relación a la de otros ámbitos habitacionales del poblado, no constatándose ningún indicio que apunte a la existencia de un interés por rescatar los elementos muebles que había en la torre en el momento de su ruina, sobre todo las armas, ornamentos o instrumentos de trabajo.

La datación del incendio se ha efectuado a partir de los materiales localizados en los últimos niveles de uso del edificio. La presencia de una ánfora greco-itálica fechada entre finales del siglo III e inicios del II a.n.e., aproximadamente entre el 210 y el 190 a.n.e., la recuperación de diversos fragmentos de kalathoi o la misma existencia sobre el pavimento de una moneda, pese a la imposibilidad de identificarla, nos encuadra este hecho dentro de un momento histórico de fuerte convulsión en las tierras del Ebro: desde la Segunda Guerra Púnica a los levantamientos indígenas del primer decenio del siglo II a.n.e.

En el caso de la guerra entre romanos y cartagineses en el curso inferior del Ebro, las fuentes clásicas citan al menos su enfrentamiento directo en este territorio en dos ocasiones: la batalla naval en la desembocadura del río o la batalla de Hibera (Diloli 2003); si bien fue posiblemente cuando los cartagineses ya habían sido expulsados de este espacio geográfico cuando los roma- 
nos tuvieron que mostrar de forma más evidente su presencia y su poder, sobre todo a raíz de los levantamientos de los caudillos ibéricos Indíbil y Mandonio, en unos hechos que también afectarían el sur del valle del Ebro.

En este sentido, cabe recordar los pasajes de la obra de Livio que nos describen como Escipión, en el año 206 a.n.e., ante la revuelta encabezada por Indíbil y Mandonio, partiendo de Cartago Nova "en diez jornadas llegó al Ebro. Después, cruzó el río y tres días después acampó a la vista del enemigo" (Livio, XXVIII, 33, 1-2), situado en el territorio sedetano (Livio, XXVIII, 31, 7), venciéndolo (Livio, XXVIII, 33-34). Tiempo después, en 205 a.n.e., se repetirían los hechos en idéntico territorio y resultado, afectando de nuevo a las áreas vecinas de la región ilergeta y a sus habitantes, entre los que cabe contar el curso inferior del Ebro, tal como relata Livio en el libro XXIX (Livio, XXIX, 1-3).

Se trata de un contexto histórico complejo, en el cual el territorio meridional catalán se debió ver profundamente alterado, pues tanto los levantamientos indígenas como el continuo paso de tropas por el mismo, debieron significar profundos cambios y transformaciones en la vida cotidiana de sus habitantes. Muy posiblemente, las alianzas de los jefes ilercavones con los caudillos ilergetas debieron suponer, ante la presencia de los ejércitos romanos, cierta conmoción para los mismos, directa o indirectamente, mediante la represión violenta o la destrucción de sus propiedades, factor que permitiría reafirmar la omnipotencia romana. En este marco podría situarse la pérdida del edificio que distinguía y simbolizaba el poder en el poblado de L'Assut, prohibiendo, por el simbolismo que ostentaba en el seno de la comunidad, su reocupación, la restitución del espacio o incluso la recuperación de los objetos de su interior. En este aspecto es interesante la cita de Apiano sobre los hechos acontecidos en este momento y sus repercusiones: "Los causantes de la rebelión fueron llevados a juicio, sus bienes, confiscados y entregados a suplicio. Se impusieron tributos a los pueblos que se habían unido a los sublevados; se les desarmó, se les exigieron rehenes y se establecieron guarniciones en ellos" (Iber, 38).

Posteriormente a estos acontecimientos, en el año 197 a.n.e. los pueblos ibéricos del nordeste peninsular se levantaron de nuevo en armas contra los romanos. Después de diversas derrotas mi- litares, Roma decidió enviar en el año 195 a.n.e. a uno de sus cónsules, Marco Porcio Catón, para solucionar el problema y acabar con la revuelta. Sobre las campañas de Catón en Hispania hay diversos datos que nos aportan los historiadores clásicos, explicando la rebelión de los pueblos ibéricos desde los Pirineos hasta el Ebro, siendo quizá el mismo Catón el que más se extiende sobre los hechos, vanagloriándose de sus hazañas (Martínez 1992), pero la acción más importante y que podríamos, hipotéticamente, relacionar con el tema que estamos tratando, es la destrucción en un solo día de todas las murallas de los poblados ibéricos del nordeste, gracias a una estratagema del general romano. Este hecho, relatado entre otros por Livio (XXXIV, 17, 11-12), Frontino (1, 1, 1), Plutarco (Cat. Mai. 10, 3), Polieno $(8,17)$ o Zónaras $(9,17)$, es perfectamente descrito por Apiano, quien nos narra el artificio del cónsul, mediante el cual "las ciudades ubicadas a lo largo del río Ebro destruyeron sus murallas en un solo día, y en el futuro, al ser muy accesibles a los romanos, quedaron durante un largo tiempo en paz" $($ Iber, 41$)$. Este podría ser el otro escenario en el cual encajaría la destrucción de la torre de L'Assut, si tenemos en cuenta la cronología de su incendio y demolición. Asimismo, difícilmente podemos atribuir a los habitantes del poblado un hecho como este, que Apiano pone en manos de los indígenas, engañados por el cónsul; en todo caso, deberíamos plantear una campaña catoniana más compleja que la relatada por el autor alejandrino, con plena implicación de las tropas romanas, que en el caso de L'Assut implicaría la presencia física de los romanos en el asentamiento, con la consecuencia de la devastación del espacio simbólico de poder y residencia del caudillo.

No podemos descartar, sin embargo, que la presencia punitiva romana en L'Assut no se efectuase con posterioridad a las campañas catonianas, pues hubo otros levantamientos que sucedieron a la presencia de este cónsul en territorio hispano. No obstante, la recuperación del ánfora greco-itálica fechada entre 210 y 190 a.n.e. en el nivel de destrucción de la torre deja un corto margen para encuadrar históricamente los hechos.

En este sentido, tanto en el caso de la Segunda Guerra Púnica como en el de los levantamientos indígenas posteriores, podemos situar otros acontecimientos que han dejado un registro arqueológico y que afectaron negativamente al desarrollo de las comunidades ibéricas del área del Ebro, 
como por ejemplo la destrucción del importante asentamiento del Castellet de Banyoles (Tivissa, Ribera d'Ebre), situado río arriba, no muy alejado del poblado de L'Assut.

El incendio provocado sobre la torre se interpretaría, pues, como una manifestación del poder romano sobre los indígenas, como una represalia destinada o bien a castigar el filopunismo de los habitantes de L'Assut, su colaboración en los levantamientos de los ilergetas y sus aliados contra los romanos o como un aviso ante la imposición de un nuevo poder, el de Roma, sobre las sociedades indígenas. Fue así, pues como, respetando aún la territorialidad indígena, se procedió a eliminar el espacio representativo del poder autóctono, plasmado en este caso mediante el simbolismo del edificio donde residía el dirigente del poblado ibérico de L'Assut, la torre T3, sin que podamos saber el destino que tuvieron sus habitantes; sin embargo, es importante resaltar la prohibición de recuperar el edificio o cualquier objeto de su interior después de la destrucción.

Como hipótesis, podríamos plantear también otras posibilidades, aunque de más fácil descarte, como una revuelta interna o un enfrentamiento entre grupos indígenas. Sin embargo, en uno y otro caso, la carencia de otros elementos indicativos de violencia en el poblado así como la ausencia de restos humanos en el interior de la torre o en otro contexto relacionado, nos dirigen a una acción externa a las relaciones entre las comunidades autóctonas.

\section{CONCLUSIONES}

La torre T3 de L'Assut se ha identificado como un espacio simbólico constituido para controlar política y económicamente una región, desde sus inicios hasta su desaparición, provocada como hemos indicado anteriormente por elementos externos al territorio. El edificio se erigió durante un horizonte cronológico que puede situarse a inicios del siglo VI a.n.e. como una edificación presumiblemente aislada, ubicada en un punto altamente estratégico, que perduró, adaptándose a un nuevo modelo urbanístico asociado a una planificación territorial organizada, hasta su destrucción alrededor del 200 a.n.e.

La construcción del edificio turriforme debe insertarse en un período confuso en que la sociedad indígena de este territorio está viviendo un ajuste socio-político a consecuencia de los importantes cambios acontecidos en el período inmediatamente anterior, la Primera Edad del Hierro, momento en el que se constata la emergencia de un sector social que se ha ido apropiando paulatinamente del control de los recursos económicos y consecuentemente del poder político.

La crisis con la que finaliza esta fase no significa una ruptura, sino un reajuste que se manifiesta durante el siglo VI a.n.e. a través de la eclosión de nuevas formas organizativas y de ejecución política que han proporcionado un registro arqueológico expresado mediante esta nueva arquitectura distintiva que son las "casas-torre" y que en las necrópolis se define a partir de la presencia de unos ajuares representativos de una aristocracia guerrera que posiblemente ocuparía estos lugares privilegiados. El nuevo grupo social o sus sucesores, directos o no, serán los que en el período posterior, ya en plena época ibérica, controlarán las formas organizativas territoriales desde los poblados, conservándose en el caso de L'Assut la referencia arquitectónica del poder a través de un edificio simbólico, la torre T3, que se integrará en el nuevo sistema defensivo sin perder el sentido residencial de un grupo privilegiado. La pervivencia de este espacio y de su simbolismo indica la continuidad de una estirpe o clan, o al menos de la idea que eso comporta.

Posiblemente el problema de este modelo, apuntado hace años por P. Moret $(2002,2006)$ radica en su innovación y regionalización, y ha sido criticado sobre todo por la falta de datos ajenos a la zona donde se apunta como un arquetipo; asimismo, los avances en la investigación en el área del Ebro y en territorios adyacentes apuestan por su revalidación. Ciertamente, el estudio del siglo VI a.n.e. en el curso inferior del Ebro cuenta con la dificultad de poder realizar apreciaciones precisas que permitan dibujar un panorama general claro a nivel territorial. De hecho, en el área que nos ocupa sólo conocemos un contexto bien definido de esta época en el Castellot de la Roca Roja (Benifallet, Baix Ebre), formado por unos materiales cerámicos en los que predominan las importaciones griegas: dos copas jonias del tipo $\mathrm{B} 2$, una copa ática del tipo $\mathrm{C}$ de Bloesch, datada hacia el 500 a.n.e., una ánfora masaliota del tipo Py 3/5, fechable entre el 475 y el 400 a.n.e., un kylix pseudo jonio y una akrocup, sin asociación a ningún resto estructural (Belarte et al. 2002: 103). El Coll del Moro de la Serra d'Almos (Ri- 
bera d'Ebre) podría responder a un modelo similar al que planteamos, localizándose en él un repertorio material compuesto básicamente por cerámica ibérica antigua acompañada de las primeras importaciones griegas. En este caso destaca la presencia de una copa ática de pie alto del tipo $\mathrm{C}$ y de un mortero de filiación griega que cabe situar hacia el 500 a.n.e. aproximadamente (Cela et al. 1999: 101). Por otro lado, en la zona del curso inferior del río Sènia, el panorama es aún más desolador, pues en el asentamiento con más presencia de la región, la Moleta del Remei (Alcanar, Montsià) hay un posible hiatus ocupacional entre mediados del siglo VI y mediados del siglo $\mathrm{V}$ a.n.e. Únicamente las necrópolis de incineración del Baix Ebre y del Montsià denotan una importante fase de cambio a partir de mediados del siglo VI a.n.e. respecto a arquetipos anteriores, a partir de los ajuares de las tumbas, que indicarían la existencia de un sector social emergente formado por una aristocracia guerrera que supuestamente dirigiría y organizaría esta región. Hasta finales del siglo $\mathrm{V}$ a.n.e. no se estructuraría este territorio políticamente y a nivel poblacional según parámetros de tipo estatal.

Por el contrario, en la zona de la Terra Alta, Matarranya y Bajo Aragón, el siglo VI a.n.e. es una etapa muy bien representada, con una red de poblamiento más densa: la Gessera (Caseres, Terra Alta), el Piuró del Barranc Fondo (Maçalió, Teruel), el Tossal del Moro (Pinyeres, Terra Alta), los últimos momentos de ocupación del Tossal Redó (Calaceit, Teruel), Sant Cristòfol (Maçalió, Teruel) o el Tossal Montañés (Valdeltormo, Teruel) son una muestra de la ocupación de este territorio en la etapa anterior al Ibérico Pleno. Tossal Montañés es el yacimiento más significativo y se ha utilizado para explicar el importante fenómeno de transformación social que conduce a la creación de un arquetipo residencial (Moret et al. 2006) del mismo tipo que el excavado en L'Assut. El edificio localizado en Valdeltormo representa el paradigma de las torres fortificadas situadas en puntos estratégicos y bien defendidos, desde donde ejercer un control de los recursos territoriales. Se vincula su construcción a la génesis de una primigenia aristocracia indígena que basaría su poder en la coerción ejercida desde el control de los recursos, los medios de producción y la tecnología, sin olvidar el simbolismo ejercido por la propia pertenencia a una élite que podría haberse gestado durante la etapa anterior. En este sentido cabe apuntar que en este territorio, por otra parte cercano a la ribera derecha del Ebro, se constata en algún caso cierta continuidad en los procesos de formación de la cultura ibérica, como ejemplifica la perduración de la necrópolis del Coll del Moro (Gandesa, Terra Alta), donde pervive sin cambios traumáticos este horizonte que representa la iberización de este espacio geográfico. Si bien compartimos algunos de estos esbozos para explicar la construcción de la torre de L'Assut por parte de un grupo de poder emergente, pensamos que la coerción material podría ser una parte del proceso de afirmación, pero que la autoridad se basaría esencialmente en una superioridad ideológica, apoyada en elementos inmateriales, y que este hecho permitiría la conservación simbólica del edificio, durante más de tres siglos, hasta su final brusco y repentino.

Nos encontramos como ya hemos apuntado ante una construcción muy similar, tanto en morfología como en cronología de construcción, a las edificaciones bautizadas con el nombre de "casas-torre" (Moret 2002). Los parecidos entre uno de los principales ejemplos de este modelo, el Tossal Montañés y L'Assut son numerosos. A nivel morfológico, se trata de construcciones turriformes de planta circular, vacías en su interior; a nivel funcional, en los dos casos son residencias, donde se evidencia la existencia de actividades económicas habituales de los recintos domésticos, como puede ser la elaboración de tejidos; a nivel cronológico, se construirían durante el mismo horizonte, el siglo VI a.n.e., si bien el edificio de Tossal Montañés sería destruido por un incendio a finales del mismo siglo o principios del siguiente. La torre de L'Assut lograría un estatus posterior incorporándose a mediados del siglo $\mathrm{V}$ a.n.e. a un poblado de nueva planta, como pasaría con la Torre de la Guardia d'Alcorisa, la cual, construida sobre un terreno inclinado, no formaba parte en un principio de un sistema defensivo, siendo en una fase más tardía cuando se insertaría en la trama urbana de un poblado que ocuparía toda la vertiente (Moret 2006: 241). Podría ser el caso también de El Palao (Alcanyís) (Moret 2005-06), el Barranc de Mosselló (Flix) (Pérez et al. 2002), o el Coll del Moro de Gandesa (Blasco y Rafel 1995).

Así pues la importancia de la torre T3 de L'Assut devendría por la perduración de un ámbito simbólico, asociado al poder ejercido por un sector de la sociedad indígena que habría surgido 
durante el siglo VI a.n.e., y que, según los datos que poseemos actualmente, podría mantenerse en el mismo sin cambios notorios, adaptándose a los nuevos parámetros político-sociales surgentes durante el siglo $\mathrm{V}$ a.n.e., ocupando el mismo espacio físico que sus antecesores hasta finales del siglo III o inicios del II a.n.e., momento en que por su propia funcionalidad representativa de las élites políticas nativas, sería destruida por un nuevo poder en proceso de afianzamiento, el romano, mediante la muestra de su capacidad militar y/o de represión.

Los acontecimientos que se sucedieron en el curso inferior del Ebro durante la Segunda Guerra Púnica y los años posteriores seguramente sirvieron para que las comunidades ibéricas de este territorio, encabezadas por sus líderes, quisieran reafirmar sus formas culturales y su fuerza frente a la presencia de elementos invasores exógenos. Este hecho también se constata en una posible reocupación de espacios funerarios antiguos, donde podría encontrarse representado el pasado heroico o mítico de estos grupos a través de los enterramientos de los antepasados (Belarte y Noguera 2007: 65). De hecho, la perduración de la torre T3 de L'Assut como un espacio simbólico de poder nos indica la existencia de un interés por parte de la élite de este asentamiento de reproducir elementos que van más allá de la autoridad material, enlazando con un posible pasado mítico del edificio y de sus antiguos propietarios, afirmando su posición social a través de la ocupación del mismo espacio, perpetuando formas arcaicas. Tal factor también puede representarse mediante la perduración de elementos ornamentales personales de prestigio, como la fíbula de resorte bilateral recuperada en la UE 1306. En este caso la materialización de la ideología del poder se expresa mediante la continuidad funcional de un edificio que simboliza un pasado heroico, guardado en la memoria colectiva y aprovechado por los grupos gobernantes de etapas posteriores, que autentifican su poder vinculándose a los primeros "señores" de la torre, tanto en el caso de tener una relación familiar directa con el grupo aristocrático antiguo, hecho ciertamente improbable, como si han obtenido su supremacía posteriormente. La propia ocupación de este espacio simbólico es una legitimización del papel político de sus residentes.

De esta manera, la destrucción del espacio representado por la torre T3 de L'Assut, eximiendo al resto del poblado, se convertiría en una muestra primordial del dominio romano sobre los grupos jerárquicos indígenas y por ende, sobre toda la población, en un momento en que Roma aún precisaría conservar la estructura organizativa de un territorio en proceso de conquista, pero bajo su control.

\section{AGRADECIMIENTOS}

Queremos agradecer la colaboración en la redacción de este trabajo a David Bea, Ethel Allué, Ramon Ferré, por sus apreciaciones poliorcéticas, David Asensio, por precisarnos la datación del ánfora greco-itálica, Samuel Sardà y a Elisa Guirao, por su interés y la traducción del texto.

\section{BIBLIOGRAFÍA}

Arcelin, CH. 1978: "Recherches sur la ceramique grise monochrome de Provence". Les cerámiques de la Grèce de l'Est et leur diffusion en Occident. París.

Bayerri, E. 1934: Historia de Tortosa y su Comarca II. Imprenta Moderna de Algueró y Baiges. Tortosa.

Bea, D. y Diloli, J. 2005: "Elements de representació durant la primera edat del ferro al curs inferior de l'Ebre: el recinte del Turó del Calvari (Vilalba dels Arcs, Terra Alta)". Revista d'Arqueologia de Ponent 15: 179-198.

Belarte, C.; Noguera, J. y Sanmartí, J. 2002: "El jaciment del Castellot de la Roca Roja (Benifallet, Baix Ebre). Un patró d'hàbitat ibèric en el curs inferior de l'Ebre". I Jornades d'Arqueologia Ibers a l'Ebre. Recerca i interpretació. Ilercavònia 3: 89-110. Tivissa.

Belarte, C. 2006: "Elementos constructivos de barro". En A. P. Moret, J. A. Benavente, A. Gorgues (eds.): Iberos del Matarraña. Investigaciones arqueológicas en Valdeltormo, Calaceite, Cretas y La Fresneda (Teruel). Al-Qannis. Taller de arqueología de Alcañiz 11. Alcañiz: 36-45.

Belarte, M.C. y Noguera, J. 2007: La necròpolis protohistòrica de Santa Madrona. Institut Català d'Arqueologia Clàssica. Tarragona.

Blasco, M. y Rafel, N. 1995: "El taller tèxtil del Coll del Moro de Gandesa (Terra Alta)". Tribuna d'Arqueologia 1993-1994: 37-50.

Castro, Z. 1985: "Pondera, examen cualitativo, cuantitativo, espacial y su relación con el telar con pesas". Ampurias 47: 230-253.

Castro, Z. 1986: "Avance de estudios cuantitativos y localización de pondera en asentamientos protohis- 
tóricos peninsulares". Arqueología Espacial 9. Coloquio sobre el microespacio 3: 169-186.

Cela, X. y Noguera, J. 1999: "Els materials arqueológics del Coll del Moro de la Serra d'Almos (Tivissa, Ribera d'Ebre): Col·lecció del Museo Comarcal Salvador Vilaseca de Reus". Pyrenae 30: 91-121.

Contreras, F.; Morales, A.; Peña, L.; Robledo, B.; Rodríguez, Ma .O.; Sanz J.L. y Trancho, G. 1996: "Avance al estudio de los ecofactos del poblado de Peñalosa (Baños de la Encina, Jaén). Una aproximación a la reconstrucción medioambiental". Anuario Arqueológico de Andalucía 1992 II. Sevilla: 263-274.

Diloli, J. 2002: Anàlisi dels models d'ocupació del territori durant la Protohistòria al curs inferior de l'Ebre. Tesi Doctoral. Edició en microforma. Universitat Rovira i Virgili.

Diloli, J. 2003: “Cartago versus Roma. El curs inferior de l'Ebre durant la Segona Guerra Púnica". Miscel-lània del CERE 16. Centre d'Estudis de la Ribera d'Ebre: 213-231.

Diloli, J. y Bea, D. 2005: “L'urbanisme d'època ibèrica al Baix Ebre: l'assentament de l'assut de Tivenys". Butlletí Arqueologic R.S.A.T. 27: 5-46.

Diloli, J.; Bea, D.; Vilaseca, A.; Arola, R. y Vilalta, E. 2002: "Primeres intervencions al jaciment protohistòric de l'Assut (Tivenys, Baix Ebre)". I Jornades d'Arqueologia Ibers a l'Ebre. Recerca i interpretació. Ilercavònia 3: 137-148. Tivissa.

Diloli, J.; Bea, D. y Vilaseca, A. 2003: El jaciment ibèric de Les Planetes (Tortosa, Baix Ebre). Viure vora el riu durant la protohistòria. Arola ed. Tarragona.

Diloli, J. y Ferré, R. 2008: “Arquitectura de las fortificaciones y sus elementos defensivos en el curso inferior del Ebro durante la época ibérica". IV Congreso internacional sobre fortificaciones. Las fortificaciones y el mar, Alcalá de Guadaira: 291-301.

Martínez Gázquez, J. 1974: La campaña de Catón en Hispania. Universitat de Barcelona. Barcelona.

Lyding Will, E. 1982: "Greco-Italic amphoras". Hesperia $V, 51: 338-357$.

Mascort, M.; Sanmartí, J. y Santacana, J. 1990: "Noves aportacions sobre el poblament protohistóric a les comarques del curs inferior de l'Ebre. Els resultats de la campanya de prospecció desenvolupada l'any 1988". La romanització del Pirineu, VIII Col-loqui Internacional d'Arqueologia de Puigcerdà (1988): 165-174. Puigcerdà.

Molinos, M. y Ruiz Rodríguez, A. 2007: Iberos en Jaén. Universidad de Jaén.

Moret, P. 2002: “Tossal Montañés y La Gessera: ¿residencias aristocráticas del Ibérico Antiguo en la cuenca media del Matarraña?’. I Jornades d'Ar- queologia Ibers a l'Ebre. Recerca i interpretació. Ilercavònia 3: 65-73. Tivissa.

Moret, P. 2005-06: "La época ibérica en El Palao (Alcañiz, Teruel)". Kalathos 24-25: 155-175.

Moret, P. 2006: “Torres circulares del Bajo Aragón y zonas vecinas: hacia la definición de un modelo regional". En A. Oliver (coord.): Arquitectura defensiva. La protección de la población y del territorio en época ibérica. Sociedad Castellonense de Cultura. Castelló de la Plana: 187-218.

Moret, P.; Benavente, J.A. y Gorgues, A. 2006: Iberos del Matarraña. Investigaciones arqueológicas en Valdeltormo, Calaceite, Cretas y La Fresneda (Teruel). Al-Qannis. Taller de arqueología de Alcañiz 11. Alcañiz.

Pons, E. 1984: L'Empordà de l'Edat del Bronze a l'Edat del Ferro 1100-600 a.C. Centre d'Investigacions Arqueològiques de Girona. Girona.

Pérez, J.M.; Rams, P. y Jornet, M. 2002: "La talàia del nucli ibèric del Barranc del Mosselló (Flix, Ribera d'Ebre)'. I Jornades d'Arqueologia Ibers a l'Ebre. Recerca i interpretació. Ilercavònia 3: 149-158. Tivissa.

Rafel, N. 1991: La necròpolis del Coll del Moro de Gandesa. Els materials, Publicacions de la Diputació de Tarragona. Tarragona.

Rafel, N. 2003: Les necròpolis tumulàries de tipus baixaragonès: les campanyes de l'Institut d'Estudis Catalans al Matarranya. Monografies del Museu d'Arqueologia de Catalunya 4. Barcelona.

Rafel, N. 2006: "Sobre el canvi en la Protohistoria. Un cas d'estudi: la primera edad del ferro com a fonament del món ibèric al Matarranya i l'Algars". De les comunitats locals als estats arcaics: la formació de les societats complexes a la costa del Mediterrani occidental. Universidad de Barcelona. Arqueomediterrània 9: 135-144.

Rafel, N. y Blasco, M. 1994: El Coll del Moro. Un recinte ibèric fortificat. Campanyes 1982-1983. Memòries d'Intervencions Arqueològiques a Catalunya 8. Generalitat de Catalunya. Barcelona.

Ramon, J. 1995: Las ánforas fenicio-púnicas del Mediterráneo Central y Occidental. Col-lecció Instrumenta 2. Universitat de Barcelona. Barcelona.

Rivera, J.M. 2007: “Aproximación a las formas constructivas en una comunidad de la Edad del Bronce: el poblado argárico de Peñalosa (Baños de la Encina, Jaén)". Arqueología y Territorio 4: 5-21.

Sanmartí, J.; Belarte, M.C.; Santacana, J.; Asensio, D. y Noguera, J. 2000: L'assentament del bronze final $i$ primera edat del ferro de Barranc de Gàfols ( $G i$ nestar, Ribera d'Ebre). Universidad de Barcelona. Arqueomediterrània 5. 